\title{
The neurobiology of adaptive learning in reading: A contrast of different training conditions
}

\author{
REBECCA SANDAK, W. EINAR MENCL, and STEPHEN J. FROST \\ Haskins Laboratories, New Haven, Connecticut \\ JAY G. RUECKL and LEONARD KATZ \\ Haskins Laboratories, New Haven, Connecticut \\ and University of Connecticut, Storrs, Connecticut \\ DINA L. MOORE \\ Haskins Laboratories, New Haven, Connecticut \\ STEPHANIE A. MASON, ROBERT K. FULBRIGHT, and R. TODD CONSTABLE \\ Yale University School of Medicine, New Haven, Connecticut \\ and \\ KENNETH R. PUGH \\ Haskins Laboratories, New Haven, Connecticut \\ and Yale University School of Medicine, New Haven, Connecticut
}

\begin{abstract}
fMRI was used to investigate the separate influences of orthographic, phonological, and semantic processing on the ability to learn new words and the cortical circuitry recruited to subsequently read those words. In a behavioral session, subjects acquired familiarity for three sets of pseudowords, attending to orthographic, phonological, or (learned) semantic features. Transfer effects were measured in an event-relatedfMRI session as the subjects named trained pseudowords, untrained pseudowords, and real words. Behaviorally, phonological and semantic training resulted in better learning than did orthographic training. Neurobiologically, orthographic training did not modulate activation in the main reading regions. Phonological and semantic training yielded equivalent behavioral facilitation but distinct functional activation patterns, suggesting that the learning resulting from these two training conditions was driven by different underlying processes. The findings indicate that the putative ventral visual word form area is sensitive to the phonological structure of words, with phonologically analytic processing contributing to the specialization of this region.
\end{abstract}

Skilled readers are characterized by the fact that they quickly and accurately recognize and comprehend written words. Neurobiologically, skilled reading seems to require the development of a highly organized cortical system that integrates processing of orthographic, phonological, and lexical-semantic features of words. This reading system includes two posterior components in the left hemisphere ( $\mathrm{LH}$ ) - a ventral (occipitotemporal) and a dorsal (temporoparietal) system - and an anterior system (centered on the LH inferior frontal gyrus; Pugh, Mencl, Jenner, et al., 2000). Previous studies have found that these regions are differentially involved in the processing of familiar and unfamiliar word stimuli and that both in-

This research was funded by NICHD Grants F32-HD42391 to R.S., R01-HD40411 to K.R.P., and P01-HD01994 to Haskins Laboratories. The authors thank Jennifer Holm, Hedy Serofin, and Terry Hickey for help in scanning the subjects and Steve Katz for help with behavioral training. Correspondence concerning this article should be addressed to R. Sandak, Haskins Laboratories, 270 Crown Street, New Haven, CT 06511-6695 (e-mail: sandak@haskins.yale.edu). creased familiarity with specific words and increased reading skill are associated with a change in the relative activation of these cortical systems, from predominantly dorsal to predominantly ventral. The present study was designed to further our understanding of the mechanisms by which this "expert" reading circuitry develops.

\section{The Ventral, Dorsal, and Anterior Reading Areas and Their Roles in Skilled Reading}

The LH ventral system includes the occipitotemporal junction (OT) and the posterior aspects of the middle and inferior temporal gyri (MTG and ITG, respectively). In skilled readers, some sites within this system (specifically, the MTG and the ITG) respond with higher activation to familiar words than to pseudowords (Fiebach, Friederici, Müller, \& von Cramon, 2002; Simos, Breier, et al., 2002; Tagamets, Novick, Chalmers, \& Friedman, 2000). These anterior temporal lobe sites are also involved in semantic processing (Price, Moore, Humphreys, $\&$ Wise, 1997). For example, Rossell, Price, and Nobre (2003) found reduced activation in this region when tar- 
get words were primed with semantically related words. A more posterior site within this system, the OT/fusiform region, appears to be especially critical to the development of fluency in word recognition and differs from the more anterior ventral regions in important ways. For example, this region responds with higher activation to unfamiliar stimuli (pseudowords) than to familiar stimuli (real words) (Brunswick, McCrory, Price, Frith, \& Frith, 1999; L. Cohen et al., 2002; Fiez, Balota, Raichle, \& Petersen, 1999; Xu et al., 2001). This region is the first to respond differentially to letter strings relative to other visual stimuli (at 150-200 msec poststimulus presentation; Salmelin, Service, Kiesila, Uutela, \& Salonen, 1996) in skilled readers but is not engaged by reading-disabled populations during tasks that require word and pseudoword reading (Paulesu et al., 2001; Salmelin et al., 1996). It has been suggested that this LH OT region functions as a presemantic visual word form area (VWFA; L. Cohen et al., 2000; but see Price, Winterburn, Giraud, Moore, $\&$ Noppeney, 2003, for an alternative account). Importantly, the functional specificity of the OT region appears to develop late and to be critically related to the acquisition of reading skill (Booth et al., 2001; Shaywitz et al., 2002); activity in this region is positively correlated with the development of reading skill in children (Shaywitz et al., 2002).

The dorsal system includes the angular gyrus and the supramarginal gyrus (SMG) in the inferior parietal lobule and the posterior aspect of the superior temporal gyrus (STG, Wernicke's area); the anterior system is centered in and around Broca's area in the inferior frontal gyrus (IFG). Sites within these systems are involved in mapping visual percepts of print onto the phonological structures of language (Benson, 1994; Black \& Behrmann, 1994; Geschwind, 1965a, 1965b), with some aspects of the anterior system associated more specifically with phonological recoding (Fiebach et al., 2002; Paulesu, Frith, \& Frackowiak, 1993; Pugh et al., 1997). In skilled readers, regions within both the LH temporoparietal system (particularly the SMG) and the anterior system (the IFG) respond with greater activity to pseudowords and low-frequency words than to familiar words (Fiebach et al., 2002; Fiez \& Petersen, 1998). In addition, these regions show heightened activity during phonological-processing tasks (Clark \& Wagner, 2003; Shaywitz et al., 1998) and reduced activity when target words are primed by phonologically similar words (Mencl et al., 2002). The fact that these regions respond more strongly to unfamiliar word stimuli and that they are engaged during tasks that involve phonological processing suggests that they are involved in the kinds of phonological analyses that are relevant to identifying and learning new words. In addition, relative to the ventral system, the dorsal and anterior systems respond to linguistic stimuli on a slower time scale: Evoked responses to words and pseudowords differ from those to nonlinguistic stimuli early in the posterior aspects of the ventral system, with responses arising later in time in the dorsal and anterior systems (Breier, Simos, Zouri- dakis, \& Papanicolaou, 1998; Dale et al., 2000; Helenius, Tarkiainen, Cornelissen, Hansen, \& Salmelin, 1999; Salmelin et al., 1996; Tarkiainen, Helenius, Hansen, Cornelissen, \& Salmelin, 1999). Taken together, these findings suggest that the dorsal and the anterior systems act in concert to recognize printed words by means of a relatively slow, computationally demanding process. We propose that these systems are critical during learning, most likely serving to extract the relationships between orthographic and phonological forms (Pugh, Mencl, Jenner, et al., 2000).

\section{Cortical and Behavioral Changes Associated With Increased Reading Skill and Word Familiarity}

Beyond demonstrating that familiar and unfamiliar word stimuli are differentially processed by ventral and dorsal/anterior regions, research has shown that increased familiarity with words (both assessed developmentally and manipulated experimentally in skilled adult readers) is associated with a shift in the relative activation of these cortical systems. In normally developing children, the dorsal and anterior systems predominate during initial reading acquisition (when most written words are relatively unfamiliar). As children become more proficient at word recognition, the ventral system plays a more prominent role in reading. In a crosssectional study in which developmental changes in the LH response to print stimuli were examined in $7-$ to 17-year-olds, Shaywitz et al. (2002) found that during reading tasks, young, normally developing children exhibited strong engagement of the dorsal and anterior systems but showed limited engagement of the ventral system. In contrast, older children tended to show increased engagement of the ventral system, particularly the $\mathrm{LH}$ OT region. Importantly, activation in this OT region was positively correlated with reading skill, so that greater activation was associated with higher reading scores. Thus, a beginning reader on a successful trajectory employs a widely distributed cortical system for print processing, including LH temporoparietal, frontal, and right hemisphere $(\mathrm{RH})$ posterior areas. As reading skill increases, these regions seem to play a diminished role, whereas LH ventral regions become more critical in the recognition of printed (word) stimuli (see also Booth et al., 2001; Turkeltaub, Gareau, Flowers, Zeffiro, \& Eden, 2003).

This developmental shift in the neurobiology of reading parallels behavioral changes in word-reading proficiency. Coincident with the increased functional role of the ventral system, readers develop into more fluent, expert readers. Behavioral studies have revealed that beginning and expert readers exhibit differences in the cognitive processes underlying word recognition. For example, increased reading skill is associated with a reduction in the robustness of the classic regularity effect. The regularity effect refers to the finding that response latencies tend to be faster for words that follow spelling-to-sound correspondence 
rules (e.g., mill) than for irregular or "exception" words (e.g., pint), whose pronunciations deviate from these rules. The regularity effect, when it is found, can be taken as evidence that the recognition process involves computationally demanding subword phonological assembly in the course of lexical access. Waters, Seidenberg, and Bruck (1985) found that whereas beginning readers exhibited strong effects of spelling-to-sound regularity on both low- and high-frequency words, older, more highly skilled readers showed diminished regularity effects on high-frequency words (suggesting a shift to more efficient processing for the most familiar words), and the most skilled readers showed diminished regularity effects on both low- and high-frequency words. Thus, there is behavioral evidence for a developmental shift from phonologically analytic to memory-based processing with increased word-reading proficiency. This finding is often interpreted as reflecting increasingly proficient mapping of orthography to phonology (Harm \& Seidenberg, 1999; Van Orden, Pennington, \& Stone, 1990).

Neurobiologically, a shift from predominantly dorsal to predominantly ventral activation is also evident when familiarity for words is increased experimentally in skilled readers (Poldrack \& Gabrieli, 2001). In a recent study from our lab group (Katz et al., 2003), we found evidence for this shift as skilled readers acquired familiarity for words via repetition. In that study, we examined repetition effects (comparing activation for thricerepeated words relative to unrepeated words) in both lexical decision (word/nonword discrimination) and overt naming. Across tasks, repetition was associated with facilitated processing, as measured by reduced response latencies and errors. Several sites, including the IFG, the SMG, the supplementary motor area (SMA), and the cerebellum, showed reduced activation for highly practiced items. Many of these are precisely the same regions that modulate with phonological priming and show increased activation during phonologically demanding processing, such as reading unfamiliar word stimuli, naming words with spelling-to-sound irregularities, and making rhyme judgments. Accordingly, we concluded that the reduced activation in these regions reflected relatively increased phonological-processing efficiency. Critically, a dissociation was seen within the ventral system. The putative VWFA in the OT region showed practice-related reduction (like the SMG and IFG sites), whereas more anterior ventral sites, particularly the MTG, were stable or increased slightly with repetition. Thus, we concluded that a neural signature of increased efficiency in word recognition is relatively reduced activation (i.e., more efficient processing) in dorsal, anterior, and posterior ventral sites, with stable or increased activation in anterior ventral sites.

These neurobiological changes associated with increased word familiarity parallel behavioral findings; behavioral studies have demonstrated that the efficiency with which a word will be identified depends on the fa- miliarity of the stimulus. For example, comparisons of low- and high-frequency words have revealed longer lexical decision and naming latencies and a greater effect of spelling-to-sound regularity for low-frequency words (Jared, 1997; Seidenberg, Waters, Barnes, \& Tanenhaus, 1984); these findings have been interpreted as evidence for predominantly phonologically mediated, algorithmic processing of infrequent words but predominantly memorybased processing of frequent (familiar) words (Coltheart, Curtis, Atkins, \& Haller, 1993). Thus, as compared with high-frequency words, low-frequency words appear to place stronger demands on subword phonological assembly. As individuals acquire familiarity for a specific word (e.g., after multiple exposures), this behavioral marker of subword phonological processing is reduced or eliminated. For example, in our recent study (Katz et al., 2003), when participants were required to make lexical decisions, the initial latency disadvantage for low-frequency, irregularly spelled words disappeared with repetition.

\section{How Does the Reading Circuit Learn?}

As was summarized above, previous research has converged on the finding that the development of skilled word reading is associated with a shift in the relative prominence of LH dorsal and anterior regions to LH ventral regions: Developmentally, as children's reading proficiency increases, the ventral regions (especially the OT region) become increasingly engaged for reading tasks. In skilled readers, the ventral system has already developed a specialization for word identification, and it is engaged during reading tasks; increased familiarity for a specific word is associated with more efficient processing (lower absolute levels of activity) in the OT region and in dorsal and anterior areas. This reflects a general learning phenomenon: (1) The acquisition of cognitive skills (as seen developmentally) is associated with increased activation in task-specific cortical areas; (2) itemspecific processing efficiency (as induced by repetition priming) is associated with relatively reduced activation in those same cortical regions (Poldrack \& Gabrieli, 2001; Poldrack, Selco, Field, \& Cohen, 1999).

The present experiment was designed to elucidate the processes by which the cortical reading system comes to read new words by providing a more precise characterization of how practice with unfamiliar words influences the relative involvement of cortical regions during reading. Specifically, it tested the hypothesis that the type of processing engaged in when a new word is learned mediates (1) how well that word is learned and (2) the cortical regions engaged when that word is subsequently read. To that end, we examined practice effects on unfamiliar pseudowords while the extent to which subjects attended to orthographic, phonological, and semantic characteristics was varied systematically over repeated exposures. Prior to fMRI scanning, the subjects acquired familiarity for three sets of pseudowords through multiple exposures, with the information coded during these 
exposures being manipulated: The subjects repeatedly performed one of three simple judgment tasks (orthographic, phonological, or semantic) for each item, resulting in multiple (eight) exposures to each pseudoword (see the Procedure section below). We then examined the effects of this differential processing on a transfer task that was not directly related to the training: Upon completion of behavioral training, the subjects completed an event-related fMRI session in which they were required simply to read aloud trained pseudowords, untrained pseudowords, and real words. With this design, we directly examined (1) how the type of processing during learning differentially mediates how well new words are learned (assessed behaviorally with accuracy and reaction time [RT] measures) and (2) differences in the mechanisms by which those words are subsequently read (by identifying the cortical regions engaged when the subjects subsequently read these items).

Regardless of training condition, we expected all of the major reading-related cortical regions to be engaged when the subjects named trained pseudowords. Our conditionspecific predictions rely on relative differences in the degree of activation within these regions. Because both phonological processing and semantic processing have been shown to engage the dorsal and anterior "learning" regions, and because theories of word learning and reading acquisition stress the importance of phonological and semantic processing, we predicted that learning conditions that stressed phonological or semantic analysis would result in the most learning and, hence, reduced naming latencies. This facilitation, in turn, would be associated with cortical activation patterns similar to those characteristic of increased efficiency of word recognition (relatively reduced activation in the SMG, the IFG, and the OT region, but stable or increased activation in the MTG and the ITG; Katz et al., 2003). Above all, because of its critical role in skilled reading, we expected better learning to be associated with reduced activation (more efficient processing) in the LH OT region. Conversely, we hypothesized that despite an equivalent number of exposures, items trained with a focus on orthographic features would not be learned as well as items trained with a focus on either phonological or semantic features and, thus, would show relatively little change in dorsal or ventral response. With regard to the specific effects of phonological and semantic training, we note several possible outcomes. Because of its central role in word learning and word reading, and because word naming inherently requires the computation of a word's phonological form, attention to a word's phonological features might considerably facilitate a shift to efficient rapid word identification. On the other hand, because a critical goal of reading is the access of meaning, emphasizing semantic processing during learning might result in the most efficient word identification. Likewise, it is possible that increased processing efficiency within the ventral system would not take place unless the meaning of the word was also activated; in our manipulation, the semantic training condition was the only one that required semantic processing and encouraged the establishment of semantic representations of some sort. Moreover, we suspected that because of the visual nature of the "semantic representations" established as a result of the semantic training in this study (see the Method section for details), the semantic training might also modulate activation in regions associated with the processing of highly imageable real words.

\section{METHOD}

\section{Subjects}

Twenty neurologically normal native English speakers (11 males and 9 females) participated in this study after giving informed consent; all experimental protocols were approved by the Yale University Human Investigation Committee. The subjects ranged in age from 16 to 48 years (median age: 22 years). None of the subjects reported a history of reading disabilities. Three additional subjects completed the study, but their data were not analyzed. One of these subjects exhibited excessive motion during MRI scanning, 1 failed to perform above chance during the behavioral training, and 1 had a history of reading disability.

\section{Materials}

Prior to completing the MRI portion of the study, the subjects completed a behavioral training session. The subjects were exposed to 123 pronounceable pseudowords and were required to attend selectively to orthographic, phonological, or semantic characteristics of each item (the procedure is described below). All the pseudowords were made up of 4-6 letters $(M=4.41, S D=0.56)$, with neighborhood densities (cf. Coltheart, Davelaar, Jonasson, \& Besner, 1977) ranging from 4 to 8 words $(M=5.76, S D=1.43)$. Items were quasi-randomly assigned to one of three groups that were matched on number of letters $[F(2,120)=0.18, p=.83]$ and neighborhood density $[F(2,120)=2.04, p=.13]$. The items were counterbalanced in such a way that a given subject encountered each pseudoword in only one training condition and each pseudoword occurred equally often in the three training conditions across subjects.

For the MRI portion of the study, three of the trained items were randomly eliminated from the stimulus set (one from each group) so that there were 40 items per training condition. Two additional sets of stimuli were used: 40 untrained pronounceable pseudowords (i.e., not presented during behavioral training) and 96 real words (48 low and 48 high in imageability). The untrained and the trained pseudowords were matched on initial letter/phoneme and did not differ in length or neighborhood density (all $p \mathrm{~s}>0.5$ ). The real words were low in frequency (range $=5-15$ occurrences per million; Kučera \& Francis, 1967). Half of the real-word items were highly imageable $(M=604.76, S D=14.58)$ and highly concrete $(M=595.24, S D=27.31 ;$ MRC psycholinguistic database, based on the norms reported by Gilhooly \& Logie, 1980, Paivio, Yuille, \& Madigan, 1968, and Toglia \& Battig, 1978), whereas the other half was low in imageability $(M=398.00, S D=35.13)$ and concreteness $(M=352.17, S D=42.30)$, with the two sets of items differing reliably on these dimensions, but not on frequency or length in letters. In addition, all the stimulus conditions were matched on length in letters.

\section{Procedure}

Behavioral training. During behavioral training, the subjects acquired familiarity for trained pseudoword items through repeated exposures. The information to which the subjects attended during 
these exposures varied systematically: The subjects repeatedly performed one of three simple judgment tasks on each item, resulting in multiple (eight) exposures to each item in a given training condition. The experimental tasks were presented using PsyScope software (J. D. Cohen, MacWhinney, Flatt, \& Provost, 1993) on a Macintosh computer. On every trial, a target pseudoword was presented on the computer screen above a comparison pseudoword, with the characteristics of the comparison item differing according to the task demands of the training condition (see Figure 1 for an illustration). As is illustrated in Figure 1A, in the orthographic training condition, the subjects made judgments about the pattern of consonants and vowels in a set of pseudowords (e.g., Is the target item a CCVCV? where CCVCV is a comparison item). In the phonological training condition, the subjects made rhyme judgments (e.g., Does the target item rhyme with BROAT? where BROAT is a comparison item; see Figure 1B). And in the semantic training condition, which involved intentional learning, they learned a novel semantic association for each pseudoword: first, each of the 41 pseudowords in this condition was associated with a unique picture that represented its "meaning" (one presentation per item; see Figure 1C, top panel), and then the subjects made semantic category judgments about those items (e.g., Is the target item a BUG?, where BUG is a comparison item; eight repetitions per item; see Figure 1C, bottom panel). The subjects indicated whether or not the target pseudoword matched the comparison item by pressing one of two buttons on a buttonbox with \pm 1 -msec accuracy. In all three conditions, corrective feedback was provided to encourage attention to the targeted feature; in the semantic condition, the picture of the "meaning" of each item was displayed with the feedback so that the subjects could learn the meanings as they proceeded through the task. Both accuracy and RTs were recorded during behavioral training. The subjects completed a set of six practice trials per condition to familiarize themselves with the experimental tasks immediately prior to completing the experimental trials. Total time for the training session was approximately $2.5 \mathrm{~h}$.

Across all repetitions within each condition, the number of yes and no responses was equated. The subjects completed all the trials for each training condition in a separate block, with three training blocks in all. There were 41 items presented in each of the three conditions, with eight exposures per item. Within each set of 41 trials, every item was presented once, in random order. Order of training blocks was counterbalanced across subjects.

fMRI session. One to $2 \mathrm{~h}$ after completing behavioral training, the subjects completed a 1.5 -h long fMRI scanning session. In this event-related fMRI session, the transfer effects of the training manipulation were measured during performance of a simple overt naming task: The subjects were required to name aloud trained pseudowords, untrained pseudowords, and high- and low-imageable real words. We employed naming as the fMRI task because it was a relatively easy task, on which performance was not directly related to training, and because we wanted to avoid tasks that required judgment and decision making (Balota \& Chumbley, 1984). In this way, we examined the ways in which attention to different features during learning transfers to subsequent naming of trained pseudowords. The experimental tasks were presented using PsyScope software (J. D. Cohen et al., 1993) on a Macintosh computer, and the stimuli were projected onto a screen outside of the scanner. There were eight runs in the fMRI portion of the experiment, with a total of 244 activation trials and 60 null trials (Friston, Holmes, \& Worsley, 1999). We also employed (1) interleaved acquisition, to increase the effective sampling rate of the hemodynamic response (Josephs, Turner, \& Friston, 1997), and (2) multiple randomized or "jittered" trial durations ( 9 or $10 \mathrm{sec}$ ), to facilitate analysis (Miezin, Maccotta, Ollinger, Petersen, \& Buckner, 2000). Each stimulus was preceded by a 1 -sec fixation (+) and was displayed for $1 \mathrm{sec}$. In Runs $1-5$, the subjects named trained and untrained pseudowords; in Runs 6-8, they named real words (high- and low-imageable items were presented in random order across these three runs).

\section{Image Acquisition}

Functional imaging was performed on a 1.5 Tesla Signa MR imaging system from General Electric Medical Systems (Waukesha, WI). Prior to functional imaging, 20 axial-oblique anatomic images (echo time, $14 \mathrm{msec}$; repetition time, $500 \mathrm{msec}$; field of view, $20 \mathrm{~cm}^{2}$; 7-mm-thick contiguous slices; matrix size, $256 \times 256 \times 2$ number of excitations) were prescribed parallel to the intercommissural line based on sagittal localizer images (echo time, $14 \mathrm{msec}$; repetition time, $500 \mathrm{msec}$; field of view, $24 \mathrm{~cm}^{2}$; 5-mm-thick contiguous slices; matrix size, $256 \times 256 \times 1$ number of excitations). The axial-oblique images were obtained at the same relative slice locations in each subject, extending from the inferior aspect of the temporal lobes to the parietal convexity. Activation images were collected using single shot, gradient echo, echo planar acquisitions (flip angle, $60^{\circ}$; echo time, $50 \mathrm{msec}$; repetition time, $2,000 \mathrm{msec}$; field of view, $20 \mathrm{~cm}^{2}$; 6-mm-thick contiguous slices; matrix size, $64 \times 64 \times 1$ number of excitations) in the same slice locations as those used for anatomic images, resulting in 183 images obtained per 6:06-min-long run.
A. Othographic

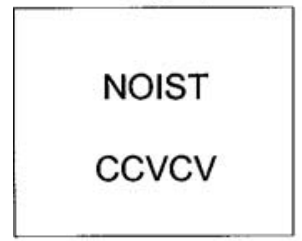

B. Phonological

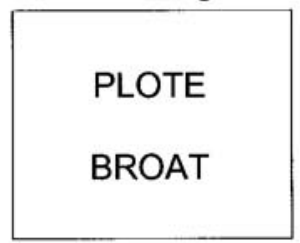

C. Semantic

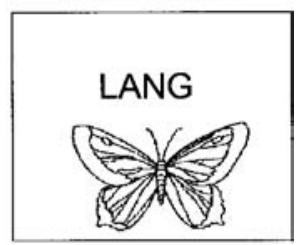

LANG

BUG

Figure 1. Illustration of the training conditions. 


\section{Image Analysis}

Data analysis was performed using software written in MATLAB (MathWorks, Natick, MA). Prior to analysis, the images from each run were motion corrected for three translation directions and for the three possible rotations with SPM-99 (Friston et al., 1995) and were sinc-interpolated to correct for slice acquisition time. The images were spatially filtered using a Gaussian filter of full width at half maximum of $3.125 \mathrm{~mm}$. Removal of low-frequency drift was effected at the subject analysis stage (see below) by first-, second-, and third-order polynomial detrending within each run. Anatomic images and single-subject activation maps were transformed into a proportional three-dimensional grid (Talairach \& Tournoux, 1988), first by in-plane transformation and then by slice interpolation into 12 slices of Talairach space, centered at $z=+68,+59,+50,+41$, $+32,+23,+14,+5,-5,-16,-27$, and $-38 \mathrm{~mm}$.

For single-subject event-related analysis, a regression-based method was used, which allows direct estimation of the hemodynamic response for each trial type, at each voxel separately, without prior specification of a reference function (Miezin et al., 2000). Time course estimates were made for $1-\mathrm{sec}$ intervals from -5 to $+15 \mathrm{sec}$ relative to trial onset. To create subject activation maps of the evoked response for each condition, we obtained regression estimates of the mean difference in these time course estimates for an activation period (4-8 sec after trial onset) relative to a baseline period ( $0-3 \mathrm{sec}$ prior to trial onset). Linear contrasts for effects of interest, including simple subtractions among trial types, main effects, and interactions, were applied to these regression estimates to obtain contrast images for each subject. This smaller set of images served as the input for subsequent across-subjects analysis of variance (ANOVA) and correlational analyses. For examination of across-subjects effects, each voxel in these contrast images was tested versus zero with an $F$ test (Holmes \& Friston, 1998; Woods, 1996), implementing a mixed model or repeated measures ANOVA (Kirk, 1982).

\section{RESULTS}

\section{Behavioral Training}

Mean accuracy and RT for each training condition at each exposure are illustrated in Figures $2 \mathrm{~A}$ and 2B, respectively. Separate repeated measures ANOVAs were computed with accuracy and RTs for correct responses as dependent measures. Training condition and exposure were entered as within-subjects factors; block order and stimulus set were counterbalanced across subjects and were thus entered into the model as between-subjects factors. Because block order and stimulus set were included in the analysis to control for any effects of these factors but were not theoretically interesting and did not qualify our effects of interest, interactions involving these two factors will not be reported.

Accuracy. A $3 \times 8 \times 3 \times 3$ (training condition $\times$ exposure $\times$ block order $\times$ stimulus set) ANOVA with accuracy as the dependent variable yielded reliable main effects of training condition $[F(2,22)=130.99, p<$ $.001]$ and exposure $[F(7,77)=60.35, p<.001]$ and a reliable interaction of training condition and exposure $[F(14,154)=60.56, p<.001]$. In general, accuracy in the orthographic and phonological training conditions was near ceiling across exposures, whereas accuracy reliably increased in the semantic training condition; this pattern was consistent with our expectation that the subjects would learn the semantic associations during semantic training. Planned paired-samples $t$ tests revealed no differences among the three training conditions by the eighth exposure.

Reaction time. A $3 \times 8 \times 3 \times 3$ (training condition $\times$ exposure $\times$ block order $\times$ stimulus set) ANOVA with RT as the dependent variable yielded reliable main effects of training condition $[F(2,20)=16.48, p<.001]$ and exposure $[F(7,70)=17.13, p<.001]$ and a reliable interaction of training condition and exposure $[F(14,140)=$ $5.51, p<.001] .{ }^{1}$ Planned repeated measures ANOVAs revealed that across exposures, RTs decreased reliably in each of the three training conditions [orthographic, $F(7,77)=11.81, p<.001 ;$ phonological, $F(7,77)=$ $2.23, p<.05$; semantic, $F(7,77)=10.37, p<.001]$. An inspection of the means indicated that the condition $X$ exposure interaction was driven by an attenuated reduction in RTs during phonological training (see Figure 2B). Planned paired-samples $t$ tests revealed differences in difficulty among the three training conditions: By the end of training (the eighth exposure), RTs were shorter for phonological training, relative to orthographic $[t(19)=$ $3.21, p<.01]$ and semantic $[t(18)=-5.07, p<.001]$ training, whereas there was no difference in RTs between orthographic and semantic training $[t(18)=-1.61, p>$ $.05]$.

Naming pilot data. Because we were unable to obtain accuracy and RT data while the subjects performed the naming task in the MRI scanner, we had a pilot cohort (31 undergraduates from the University of Con-
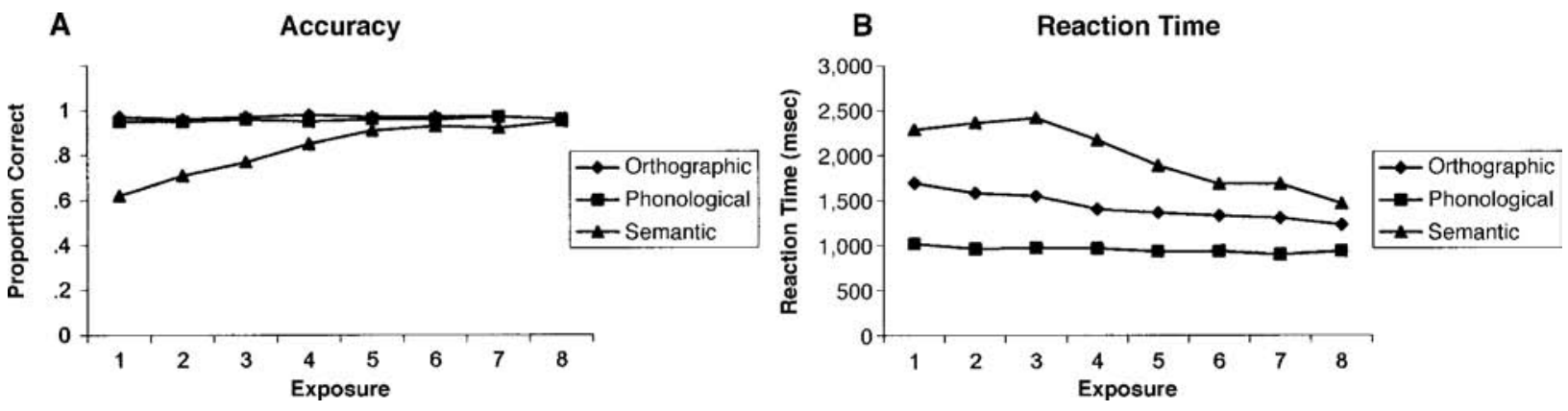

Figure 2. Mean accuracy and reaction time by training condition and exposure. 
necticut) complete the same behavioral training; we then collected behavioral data as they named the trained items out-of-magnet. Analyses confirmed that during training, the two cohorts performed fairly similarly. A $3 \times 8 \times$ $3 \times 3 \times 2$ (training condition $\times$ exposure $\times$ block order $\times$ stimulus set $X$ cohort) repeated measures ANOVA with accuracy as the dependent measure revealed a main effect of cohort $[F(1,33)=32.44, p<.001]$ such that the MRI cohort $(M=0.92)$ was more accurate than the pilot cohort $(M=0.87) .^{2}$ The groups did not differ in their overall RTs $(F<1) .{ }^{3}$ The naming effects reported below are from the pilot cohort.

Naming response latencies less than $200 \mathrm{msec}$ and greater than $1,750 \mathrm{msec}$ were discarded as outliers. These outliers comprised less than $1.5 \%$ of all the responses. An additional 47 trials (1.2\% of all the responses) were discarded due to microphone failure. For the RT analysis, trials on which an error occurred were also discarded. Data from 1 subject were excluded due to excessive naming errors $(10 \%$ overall and $21 \%$ for items encoded orthographically). In the ANOVA, there was no interaction between block order or stimulus set and the other independent variables (all $p \mathrm{~s}>.10$ ), enabling us to combine the data across these subgroups.

The mean naming times for these subjects in the orthographic, phonological, and semantic training conditions were $631 \mathrm{msec}(S D=100 \mathrm{msec}), 620 \mathrm{msec}(S D=$ $84 \mathrm{msec})$, and $620 \mathrm{msec}(S D=89 \mathrm{msec})$, respectively. A repeated measures ANOVA revealed a marginal main effect of training condition on naming time $[F(2,29)=$ $2.90, p=.06] .{ }^{4}$ Planned comparisons were consistent with our a priori hypothesis that there would be reliable training effects, with reduced naming times following training for the phonological and semantic, relative to the orthographic, training conditions $[F(1,29)=4.36$, $p<.05$, and $F(1,29)=4.34, p<.05$, respectively]. Thus, despite the fact that training was irrelevant to performance of the naming task, we observed transfer effects of the training condition. In addition, there was no difference in naming times between the phonological and the semantic conditions $(F<1)$, with the mean naming times nearly identical for these two conditions. Importantly, the observed differences in naming time did not reflect a speed-accuracy tradeoff. Naming accuracy was high in all conditions $[M=0.97(S D=0.02)$ for orthographic, $M=0.96(S D=.03)$ for phonological, and $M=0.96(S D=.04)$ for semantic]. A separate repeated measures ANOVA revealed no effect of training condition on naming accuracy $(p>.5)$; planned comparisons were consistent with this finding, revealing no differences in naming accuracy among training conditions (all $p$ s > .10). We assume that similar patterns would have been obtained in the fMRI cohort. ${ }^{5}$

\section{f MRI Results}

General training effects. Displayed from left to right in Figure 3 are maps of the evoked responses to untrained pseudowords, trained pseudowords (collapsed across the three training conditions), and real words (col-

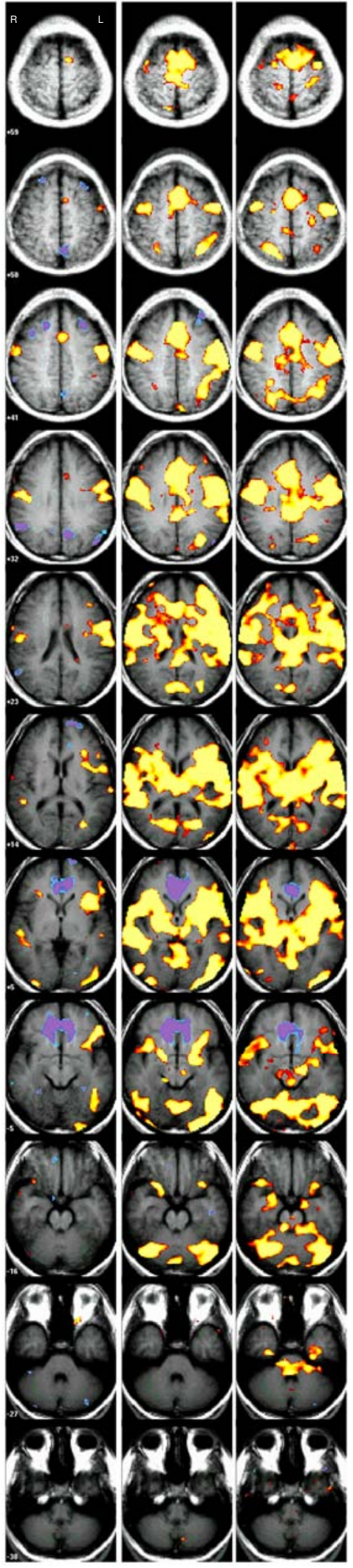

Figure 3. Evoked response maps for untrained pseudowords, trained pseudowords (collapsed across training conditions), and real words (collapsed across imageability). 
lapsed across low and high imageability). In this figure, areas colored in red/yellow were more active 4-8 sec poststimulus than during prestimulus baseline time points; areas colored in blue/purple were less active $(p<.01$, uncorrected). As per radiological convention, in this and all the subsequent figures of fMRI activation, the images are oriented with the LH displayed toward the right and the RH displayed toward the left. Overall, the training resulted in a pattern of cortical activation during naming that was intermediate to those for untrained pseudowords and real words, with trained pseudowords showing activation that was more similar to that for real words than to that for novel pseudowords. We confirmed this observation by quantifying the similarity of activation patterns between each pair of these evoked response maps, operationalizing similarity as the proportion of similarly active voxels [all voxels that were active $(p<$ .01 , uncorrected) or inactive ( $p>.5$, uncorrected) in each map] to the total number of voxels. The highest degree of similarity was observed between trained pseudowords and real words (.26), followed by novel and trained pseudowords (.14), with the least similarity between novel pseudowords and real words (.10).

The naming of trained pseudowords activated many regions found to be active in the naming of real words that either were not reliably active or were only minimally active for the naming of untrained pseudowords. These include the bilateral SMG, the bilateral IFG, the precentral gyrus, the bilateral insula and STG, the bilateral lingual gyrus, and the LH MTG. Thus, the training resulted in increased activation at many reading-related sites.

It is also worth noting that we observed markedly less activation for novel pseudowords than for real words. This finding was unexpected (several previous studies had found greater overall cortical activation during pseudoword reading than during real-word reading; e.g., Price, Wise, \& Frackowiak, 1996; Rumsey, Horwitz, et al., 1997; Tagamets et al., 2000) but was very robust within this data set (for $90 \%$ of voxels, mean activation was numerically higher for real words than for untrained pseudowords). It is possible that behavioral training on pseudowords influenced the way in which all the pseudowords were processed during the subsequent $\mathrm{fMRI}$ session. As a result, further analyses contrasting the training conditions with untrained pseudowords will not be reported. The comparisons of interest, described below, directly compare activation patterns observed for the three different training conditions, in which stimulus characteristics and number of exposures were matched.

Training-specific effects. Because the task completed during MRI scanning (overt naming) was identical across conditions, it is not surprising that there were many foci of overlapping activation for the three training conditions. More interesting, with respect to our goal of understanding the functional role of different cortical regions within the reading circuit, are those regions that were relatively more or less active for only one or two of the training conditions. These regions probably reflect the consequences of the type of processing that was em-

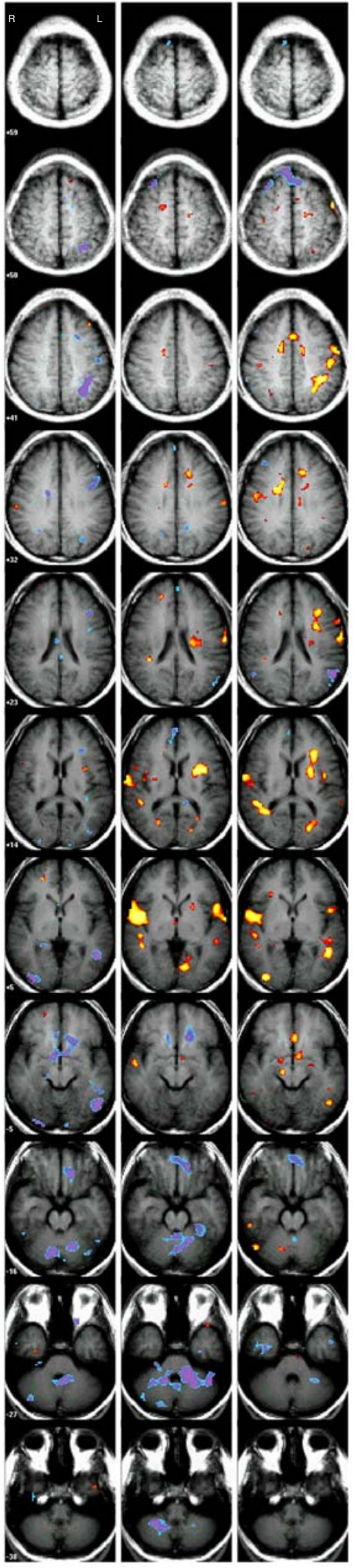

Figure 4. Training-specific contrast maps: from left to right, orthographic versus phonological, orthographic versus semantic, and phonological versus semantic. 
phasized during learning and are likely to be critical for training these different types of codes. Figure 4 shows three direct contrast maps in which each condition is separately compared with the other two conditions, from left to right: orthographic versus phonological, orthographic versus semantic, and phonological versus semantic. Areas shown in blue/purple were relatively more active for the first condition in each comparison; areas shown in red/yellow were relatively more active for the second condition from each comparison $(p<.05$, uncorrected). Table 1 lists the regions that were differentially active in each of these comparisons.

The first column of Figure 4 directly compares items trained orthographically with items trained phonologically. Several regions were more active for items trained orthographically. In the LH, these include the SMG, the IFG, the OT region (extending from the anterior aspect of the middle occipital gyrus to the posterior aspect of the MTG), and the gyrus rectus. Relatively more activation to orthographically trained items was also observed in the right middle occipital gyrus, the bilateral anterior cingulate gyrus, and the cerebellum (bilateral hemispheres and deep nuclei). Very few regions were more active when the subjects named items trained phonologically; one worth noting is the bilateral insula.

The middle column of Figure 4 compares items trained orthographically with items trained semantically. Few regions exhibited heightened activation for orthographically trained items; these included the bilateral cerebellum (bilateral hemispheres and deep nuclei), the bilateral gyrus rectus, the bilateral anterior cingulate gyrus, and the LH angular gyrus. An examination of the evoked response maps for the two conditions indicated that the difference observed in the angular gyrus reflected relatively less deactivation (relative to baseline timepoints) for orthographically than for semantically trained items. Several regions were significantly more active when the subjects named semantically trained items, relative to orthographically trained items. These areas include the LH central gyrus, the bilateral anterior cingulate gyrus, the LH caudate body, the bilateral insula, the bilateral MTG and STG, and the LH lingual gyrus.

The third column in Figure 4 illustrates the comparison between phonologically and semantically trained items. Heightened activation for items trained phonologically was seen in the bilateral (although predominantly LH) angular gyrus. As was the case in the orthographic-semantic contrast, this difference in angular gyrus reflects a relative difference in deactivation of this region (less deactivation for phonologically than for semantically trained items). Considerably more regions exhibited heightened activation for semantically, relative to phonologically, trained items; these include the LH SMG, extending along the intraparietal sulcus, the LH precentral gyrus, the LH IFG, the bilateral anterior cingulate gyrus, the LH caudate body, the bilateral insula, the bilateral MTG, the LH OT juncture, and the RH inferior occipital gyrus.
We were particularly interested in areas that were more or less active for one of the training conditions relative to the other two. To directly examine these relatively "unique" effects of training condition, we conducted an intersection analysis in which we identified regions that were reliably activated ( $p<.05$, uncorrected) in two of the three contrasts described above (e.g., orthographic vs. phonological and orthographic vs. semantic), with a conjoint $p<.0025$, uncorrected. Each column in Figure 5 shows brain regions in which there was reliably more or less activation (shown in yellow and purple, respectively) for items trained in one training condition (from left to right: orthographic, phonological, and semantic), relative to the other two conditions (see also Table 2). As compared with both the phonological and the semantic training conditions, orthographic training was associated with heightened activation in the bilateral cerebellum (hemispheres and deep nuclei) and the LH anterior cingulate gyrus and gyrus rectus but with reduced activation in the LH insula. As compared with the other two training conditions, phonological training was associated with relatively less activation in the $\mathrm{LH}$ SMG, IFG, and OT region, and the RH middle occipital gyrus. Items encoded semantically were associated with strikingly more activation in the bilateral insula, the bilateral MTG and STG, the LH caudate body, and the LH central gyrus but with relatively less activation in the $\mathrm{LH}$ angular gyrus, relative to the other two training conditions.

The OT area: Region of interest analysis. Because of the critical role played by the LH OT region in skilled reading (Pugh, Mencl, Jenner, et al., 2000; Shaywitz et al., 2002), we conducted a region of interest (ROI) analysis to examine directly activation in this region when the subjects named items trained orthographically, phonologically, and semantically. As was noted earlier, previous cross-sectional studies (Shaywitz et al., 2002; Shaywitz, Shaywitz, Blachman, et al., 2003; Shaywitz, Shaywitz, Fulbright, et al., 2003) have identified a LH medial OT region in which activation during a rhyme judgment task was positively correlated with reading skill. Because the OT region described in these studies was specifically associated with the development of skilled reading, we used these previous findings (Shaywitz et al., 2002; Shaywitz, Shaywitz, Blachman, et al., 2003; Shaywitz, Shaywitz, Fulbright, et al., 2003) to define the OT region for our OT ROI analysis. The anatomical center of the region described in the Shaywitz et al. studies is located at the following Talairach coordinates: $x,-47 ; y,-52 ; z,-5$. The center of this region is slightly superior to, but overlaps with, the putative VWFA described by L. Cohen and colleagues (L. Cohen et al., 2000; L. Cohen et al., 2002).

Figure 6A shows the time course of activation in this region. Whereas the naming of items trained in all three conditions elicited some activation in this region, orthographically and semantically trained pseudowords elicited 
Table 1

Direct Comparisons Between Training Conditions

\begin{tabular}{|c|c|c|c|c|c|c|}
\hline Contrast & Location & $x$ & $y$ & $z$ & Volume (mm) & $p$ Value (at Peak) \\
\hline Orthographic $<$ phonological & $\begin{array}{l}\text { R. superior/middle frontal gyri } \\
\text { L. insula }\end{array}$ & $\begin{array}{r}21 \\
-30\end{array}$ & $\begin{array}{r}45 \\
3\end{array}$ & $\begin{array}{r}5 \\
14\end{array}$ & $\begin{array}{l}299 \\
271\end{array}$ & $\begin{array}{l}.0145 \\
.0219\end{array}$ \\
\hline Orthographic $>$ phonological & $\begin{array}{l}\text { R., L. globus pallidus, anterior cingulate } \\
\text { L. supramarginal gyrus } \\
\text { L. occipitotemporal gyrus } \\
\text { R. cerebellar hemisphere } \\
\text { L. cerebellar nuclei } \\
\text { R. middle occipital gyrus } \\
\text { L. inferior frontal gyrus } \\
\text { L. cerebellar hemisphere } \\
\text { R. cerebellar hemisphere } \\
\text { L. postcentral gyrus } \\
\text { L. inferior frontal gyrus } \\
\text { R. anterior cingulate gyrus } \\
\text { L. inferior frontal gyrus } \\
\text { L. cerebellar hemisphere } \\
\text { L. anterior cingulate gyrus } \\
\text { R. hippocampus } \\
\text { R. substantia nigra }\end{array}$ & $\begin{array}{r}9 \\
-28 \\
-45 \\
8 \\
-1 \\
33 \\
-38 \\
-14 \\
37 \\
-47 \\
-37 \\
4 \\
-26 \\
-37 \\
-21 \\
23 \\
16\end{array}$ & $\begin{array}{r}-2 \\
-58 \\
-50 \\
-67 \\
-52 \\
-85 \\
1 \\
-60 \\
-75 \\
-16 \\
20 \\
27 \\
25 \\
-67 \\
10 \\
-36 \\
-22\end{array}$ & $\begin{array}{r}-5 \\
41 \\
5 \\
-16 \\
-27 \\
5 \\
32 \\
-16 \\
-27 \\
41 \\
23 \\
-5 \\
14 \\
-16 \\
41 \\
5 \\
-5\end{array}$ & $\begin{array}{r}6,298 \\
3,909 \\
3,828 \\
1,955 \\
1,873 \\
1,737 \\
1,520 \\
1,357 \\
543 \\
489 \\
461 \\
461 \\
434 \\
407 \\
380 \\
326 \\
271\end{array}$ & $\begin{array}{l}.0016 \\
.0000 \\
.0002 \\
.0050 \\
.0057 \\
.0047 \\
.0115 \\
.0042 \\
.0120 \\
.0195 \\
.0067 \\
.0181 \\
.0179 \\
.0245 \\
.0145 \\
.0203 \\
.0176\end{array}$ \\
\hline Orthographic $<$ semantic & $\begin{array}{l}\text { R. superior temporal gyrus } \\
\text { L. insula/basal ganglia (putamen) } \\
\text { L. superior temporal gyrus } \\
\text { L. lingual gyrus } \\
\text { R. middle temporal gyrus } \\
\text { L. caudate } \\
\text { L. central gyrus } \\
\text { R. anterior cingulate gyrus } \\
\text { L. anterior cingulate gyrus } \\
\text { L. middle temporal gyrus } \\
\text { R. supramarginal gyrus } \\
\text { L. basal ganglia (putamen) } \\
\text { R. superior frontal gyrus } \\
\text { R. anterior cingulate gyrus }\end{array}$ & $\begin{array}{r}50 \\
-28 \\
-48 \\
-9 \\
42 \\
-20 \\
-59 \\
14 \\
-16 \\
-48 \\
33 \\
-20 \\
18 \\
13\end{array}$ & $\begin{array}{r}-2 \\
3 \\
8 \\
-65 \\
-38 \\
-15 \\
-12 \\
-8 \\
17 \\
-30 \\
-34 \\
10 \\
39 \\
4\end{array}$ & $\begin{array}{r}5 \\
14 \\
5 \\
5 \\
5 \\
23 \\
23 \\
41 \\
32 \\
5 \\
23 \\
5 \\
23 \\
32\end{array}$ & $\begin{array}{r}7,085 \\
2,307 \\
2,172 \\
1,575 \\
1,547 \\
1,357 \\
1,086 \\
760 \\
733 \\
407 \\
326 \\
326 \\
299 \\
271\end{array}$ & $\begin{array}{l}.0015 \\
.0003 \\
.0063 \\
.0051 \\
.0081 \\
.0166 \\
.0048 \\
.0233 \\
.0108 \\
.0260 \\
.0160 \\
.0242 \\
.0157 \\
.0125\end{array}$ \\
\hline Orthographic $>$ semantic & $\begin{array}{l}\text { L. cerebellar nuclei } \\
\text { L. gyrus rectus } \\
\text { R. frontal gyrus } \\
\text { R. anterior cingulate gyrus } \\
\text { R. cerebellar hemisphere } \\
\text { R. superior frontal gyrus } \\
\text { R. cerebellar hemisphere } \\
\text { R. cerebellar hemisphere } \\
\text { L. angular gyrus } \\
\text { L. precuneus }\end{array}$ & $\begin{array}{r}-11 \\
-13 \\
3 \\
11 \\
23 \\
28 \\
26 \\
40 \\
-50 \\
-13\end{array}$ & $\begin{array}{r}-40 \\
38 \\
50 \\
24 \\
-81 \\
24 \\
-24 \\
-75 \\
-67 \\
-52\end{array}$ & $\begin{array}{r}-27 \\
-16 \\
14 \\
-5 \\
-27 \\
50 \\
-27 \\
-27 \\
23 \\
32\end{array}$ & $\begin{array}{r}17,455 \\
4,452 \\
733 \\
624 \\
597 \\
597 \\
543 \\
353 \\
326 \\
299\end{array}$ & $\begin{array}{l}.0001 \\
.0086 \\
.0225 \\
.0226 \\
.0260 \\
.0034 \\
.0067 \\
.0302 \\
.0252 \\
.0223\end{array}$ \\
\hline Phonological $<$ semantic & $\begin{array}{l}\text { R. superior temporal gyrus } \\
\text { L. inferior frontal gyrus } \\
\text { L. supramarginal gyrus } \\
\text { R. anterior cingulate gyrus } \\
\text { R. superior temporal gyrus } \\
\text { L. middle temporal gyrus } \\
\text { L. anterior cingulate gyrus } \\
\text { L. precentral gyrus } \\
\text { L. lingual gyrus/calcarine fissure } \\
\text { L. postcentral gyrus } \\
\text { R. inferior frontal gyrus } \\
\text { L. central gyrus } \\
\text { R. middle occipital gyrus } \\
\text { L. anterior cingulate gyrus } \\
\text { L. anterior cingulate gyrus } \\
\text { L. anterior cingulate gyrus } \\
\text { L. superior temporal gyrus } \\
\text { L. middle temporal gyrus } \\
\text { L. central gyrus } \\
\text { R. fusiform gyrus } \\
\text { R. substantia nigra } \\
\text { R. basal ganglia (globus pallidus) } \\
\text { L. inferior frontal gyrus } \\
\text { L. anterior cingulate gyrus }\end{array}$ & $\begin{array}{r}48 \\
-26 \\
-35 \\
20 \\
42 \\
-45 \\
-13 \\
-50 \\
-21 \\
-47 \\
45 \\
-59 \\
33 \\
1 \\
-13 \\
-3 \\
-47 \\
-47 \\
-38 \\
47 \\
13 \\
14 \\
-57 \\
-8\end{array}$ & $\begin{array}{r}-4 \\
18 \\
-42 \\
-1 \\
-38 \\
-46 \\
-7 \\
-4 \\
-71 \\
-19 \\
-8 \\
-8 \\
-81 \\
10 \\
18 \\
22 \\
4 \\
-30 \\
-4 \\
-62 \\
-18 \\
-4 \\
11 \\
-15\end{array}$ & $\begin{array}{r}5 \\
14 \\
41 \\
32 \\
14 \\
5 \\
41 \\
50 \\
14 \\
41 \\
32 \\
23 \\
5 \\
41 \\
32 \\
-5 \\
5 \\
5 \\
14 \\
-16 \\
-5 \\
-5 \\
23 \\
32\end{array}$ & $\begin{array}{r}4,886 \\
4,886 \\
2,552 \\
2,525 \\
2,280 \\
2,253 \\
1,384 \\
1,330 \\
1,194 \\
1,167 \\
1,140 \\
1,004 \\
842 \\
842 \\
814 \\
760 \\
733 \\
706 \\
516 \\
461 \\
434 \\
353 \\
353 \\
326\end{array}$ & $\begin{array}{l}.0040 \\
.0033 \\
.0003 \\
.0024 \\
.0029 \\
.0026 \\
.0167 \\
.0026 \\
.0079 \\
.0056 \\
.0183 \\
.0077 \\
.0023 \\
.0099 \\
.0072 \\
.0085 \\
.0133 \\
.0221 \\
.0148 \\
.0082 \\
.0071 \\
.0262 \\
.0221 \\
.0251\end{array}$ \\
\hline
\end{tabular}


Table 1 (Continued)

\begin{tabular}{|c|c|c|c|c|c|c|}
\hline Contrast & Location & $x$ & $y$ & $z$ & Volume (mm) & $p$ Value (at Peak) \\
\hline & L. body of caudate & -23 & -15 & 23 & 299 & .0332 \\
\hline & R. cerebellar hemisphere & 14 & -63 & -16 & 271 & .0245 \\
\hline \multirow[t]{9}{*}{ Phonological $>$ semantic } & R. superior frontal gyrus & 4 & 34 & 50 & 3,203 & .0068 \\
\hline & L. gyrus rectus & -4 & 46 & -16 & 1,792 & .0164 \\
\hline & L. angular gyrus & -50 & -56 & 23 & 1,357 & .0028 \\
\hline & R. temporal pole/middle temporal gyrus & 33 & -8 & -27 & 977 & .0100 \\
\hline & R. superior frontal gyrus & 33 & 20 & 50 & 842 & .0065 \\
\hline & L. cerebellar hemisphere & -26 & -48 & -27 & 434 & .0277 \\
\hline & R. middle frontal gyrus & 33 & 29 & 32 & 380 & .0194 \\
\hline & R. angular gyrus & 48 & -56 & 23 & 299 & .0126 \\
\hline & L. temporal pole/middle temporal gyrus & -47 & -1 & -27 & 271 & .0240 \\
\hline
\end{tabular}

the most activation, and activation in this region was attenuated for phonologically trained pseudowords. This finding is consistent with the results from our intersection analyses (described above), which revealed that, as compared with the other two training conditions, phonological training was associated with relatively less activation in the LH OT region.

Imageability effects for real words. Figure 7A shows the main effect of imageability, with red/yellow indicating relatively more activation for high-imageable words and blue/purple indicating relatively more activation for low-imageable words $(p<.05$, uncorrected; see also Table 3). Areas showing heightened activation when the subjects named high-imageable concrete words included the bilateral anterior cingulate gyrus, the LH central gyrus, superior aspects of the LH IFG, the bilateral insula, the bilateral MTG and STG, the bilateral OT regions extending into the fusiform gyrus in the $\mathrm{LH}$, the bilateral lingual gyrus, the bilateral ITG, and the RH SMG and middle occipital gyri. Relatively heightened activation was seen for low-imageable words only in inferior aspects of the LH IFG and the cerebellum (bilateral hemispheres and deep nuclei).

Semantically encoded pseudowords relative to high- and low-imageable words. Areas in which there was enhanced activation for semantically trained pseudowords (relative to the other two training conditions) largely overlapped those areas that were predominantly active for high- versus low-imageable words (especially the bilateral STG; compare the rightmost columns of Figures 5 and 7). As was noted in the introduction, we had initially hypothesized that semantic training might facilitate learning because of the establishment of some form of semantic representation. Moreover, because of the presumably visual nature of the semantic representations established during semantic training, we predicted that the pattern of cortical activation for semantically trained pseudowords would be more similar to that for high-imageable real words than to that for low-imageable real words. To assess these hypotheses, we conducted a ROI analysis in which we identified the region that showed the maximal difference between high- and lowimageable real words; this independently defined functional ROI included aspects of the LH STG and MTG.
We then examined the pattern of cortical activation in this region for the three training conditions and the two real-word conditions. Figure 6B shows the time course of activation in this region: High-imageable real words and semantically trained pseudowords (for which the subjects learned semantic associations to visual pictures) were processed similarly and elicited the most activation; activation in this region was attenuated for lowimageable real words, as well as for orthographically and phonologically trained pseudowords.

In an individual-difference analysis, we correlated how well the subjects had learned the "meanings" of the semantically trained pseudowords ${ }^{6}$ with activation during the subsequent naming of those items. The results are shown in Figure 7B $(p<.05$, uncorrected; see also Table 4); we found that activation in several regions, particularly the bilateral STG and the LH MTG, was predicted by how well the subjects had learned the "meanings" of the semantically encoded pseudowords, with better learning (and presumably, richer semantic representations) associated with heightened activation in these regions (peak $r \mathrm{~s}=.50$ and .52 , respectively). Together with the overlap in functional activation between high-imageable real words and semantically trained pseudowords observed in these regions, this result suggests similarities in visuo-semantic processing between these two conditions. Interestingly, we also observed that the subjects who demonstrated the least mastery of the meanings of the semantically trained pseudowords tended to show heightened activation in a widely distributed set of regions, including the $\mathrm{RH}$ intraparietal sulcus, the cerebellum, the bilateral IFG, and the LH ITG (peak $r \mathrm{~s}=-.52,-.87,-.55$, and -.50 , respectively); these regions have been previously implicated in both attentional control (Coull, 1998; Posner \& Dehaene, 1994) and phonologically analytic and semantic processing in language (Pugh, Mencl, Jenner, et al., 2000).

\section{GENERAL DISCUSSION}

This study was designed to provide insight into the mechanisms by which the cortical reading circuit comes to process familiar words efficiently. We examined the neural activation associated with the overt naming of 


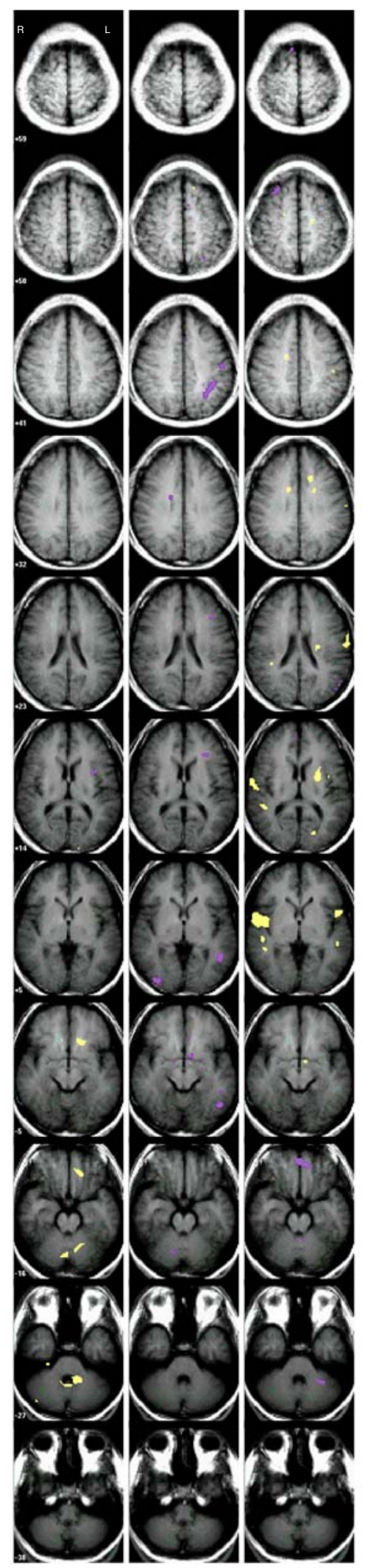

Figure 5. "Unique" effects of training: Areas showing more or less activation (in yellow and purple, respectively) for items trained in each training condition relative to the other two; from left to right, orthographic, phonological, and semantic. trained pseudowords differing only in the type of processing engaged in by learners during training. The results indicated that engaging in different types of processing (orthographic, phonological, or semantic) as a word is learned has both behavioral and neurobiological consequences. Behaviorally, we found that attention to phonological or semantic features during learning resulted in greater improvements in reading aloud than did attention to orthographic features. Neurobiologically, the phonological training condition was associated with relatively reduced activation in LH dorsal, anterior, and posterior ventral (OT) sites, a neural signature of increased processing efficiency for familiar words (Katz et al., 2003). The semantic training condition was associated with relatively increased activation in the LH STG and MTG, suggesting that the equivalent behavioral facilitation observed for semantically and phonologically trained items was driven by different underlying processes. Importantly, only phonological training, which required phonologically analytic processing of pseudowords during learning, resulted in increased efficiency (relatively reduced activation) in the OT region. Whereas previous studies have indicated that this region becomes specialized for rapid word identification in skilled readers, the results from this study are the first to provide insights into the processes by which this specialization develops.

\section{Differential Effects of Training}

As was predicted, attending to phonological or semantic features during training resulted in better learning (indexed by shorter naming latencies) than did attending to orthographic features. This finding confirms our hypothesis that superior learning of new words is achieved with attention to the phonological and semantic, rather than the orthographic, features of novel words. In addition, no behavioral difference was observed between the phonological and the semantic training conditions, suggesting that attention to phonological and semantic features during training resulted in equally good learning, as measured by the RTs for naming.

When the subjects named pseudowords learned in each of the three training conditions, a set of LH cortical sites, including the IFG, the SMG, the angular gyrus, the MTG, and the OT region, was activated. These sites have been identified in previous studies of word and pseudoword reading and were also found to be active when the subjects named untrained pseudowords and real words in the present study. Normally, these areas work together as an integrated system; by identifying activations maximally associated with each training condition, we were able to gain insight into information-processing differences among regions.

Attention to orthographic features. As compared with the other two training conditions, orthographic training resulted in relatively more activation in the bilateral anterior cingulate gyrus, the gyrus rectus, and the cerebellum. Whereas previous studies have implicated these regions in attention, visual processing, and motor planning, none of these is considered to be among the 
Table 2

Unique Activations for Each Training Condition

\begin{tabular}{|c|c|c|c|c|c|}
\hline Condition & Location & $x$ & $y$ & $z$ & Volume $(\mathrm{mm})$ \\
\hline Orthographic $<\{$ phonological and semantic $\}$ & L. insula & -31 & 6 & 14 & 271 \\
\hline Orthographic $>$ \{phonological and semantic $\}$ & $\begin{array}{l}\text { L. cerebellar hemisphere } \\
\text { L. anterior cingulate } \\
\text { L. gyrus rectus } \\
\text { L. cerebellar hemisphere } \\
\text { Vermis } \\
\text { R. cerebellar nuclei } \\
\text { R. cerebellar nuclei } \\
\text { R. cerebellar hemisphere } \\
\text { L. cuneus/middle occipital gyrus } \\
\text { R. cerebellar nuclei } \\
\text { R. cerebellar nuclei } \\
\text { R. anterior cingulate }\end{array}$ & $\begin{array}{r}-9 \\
-11 \\
-8 \\
-14 \\
3 \\
6 \\
26 \\
40 \\
-13 \\
8 \\
9 \\
8\end{array}$ & $\begin{array}{r}-40 \\
25 \\
39 \\
-54 \\
-65 \\
-52 \\
-22 \\
-73 \\
-95 \\
-50 \\
-48 \\
24\end{array}$ & $\begin{array}{r}-27 \\
-5 \\
-16 \\
-16 \\
-16 \\
-27 \\
-27 \\
-27 \\
14 \\
-27 \\
-27 \\
-5\end{array}$ & $\begin{array}{r}869 \\
597 \\
597 \\
489 \\
461 \\
326 \\
109 \\
81 \\
27 \\
27 \\
27 \\
27\end{array}$ \\
\hline Phonological $<\{$ orthographic and semantic $\}$ & $\begin{array}{l}\text { L. supramarginal gyrus } \\
\text { L. middle temporal gyrus } \\
\text { R. middle occipital gyrus } \\
\text { L. postcentral gyrus } \\
\text { L. inferior frontal gyrus } \\
\text { R. anterior cingulate } \\
\text { L. inferior frontal gyrus } \\
\text { R. cerebellar hemisphere } \\
\text { L. middle temporal gyrus } \\
\text { L. intraparietal sulcus } \\
\text { R. basal ganglia (globus pallidus) } \\
\text { L. superior frontal gyrus } \\
\text { L. anterior cingulate } \\
\text { R. hippocampus } \\
\text { L. precentral gyrus } \\
\text { L. anterior cingulate } \\
\text { L. supramarginal gyrus } \\
\text { R. substantia nigra }\end{array}$ & $\begin{array}{r}-37 \\
-43 \\
37 \\
-47 \\
-25 \\
18 \\
-33 \\
14 \\
-43 \\
-25 \\
13 \\
-4 \\
-3 \\
23 \\
-35 \\
-6 \\
-25 \\
14\end{array}$ & $\begin{array}{r}-36 \\
-44 \\
-77 \\
-15 \\
27 \\
-4 \\
22 \\
-63 \\
-38 \\
-62 \\
-2 \\
4 \\
13 \\
-36 \\
-1 \\
25 \\
-42 \\
-19\end{array}$ & $\begin{array}{r}41 \\
5 \\
5 \\
41 \\
14 \\
32 \\
23 \\
-16 \\
-5 \\
50 \\
-5 \\
50 \\
41 \\
5 \\
23 \\
-5 \\
41 \\
-5\end{array}$ & $\begin{array}{r}1,656 \\
1,439 \\
733 \\
407 \\
353 \\
271 \\
217 \\
190 \\
136 \\
109 \\
81 \\
81 \\
81 \\
54 \\
54 \\
54 \\
27 \\
27\end{array}$ \\
\hline Phonological $>\{$ orthographic and semantic $\}$ & L. superior frontal gyrus & -11 & 25 & 50 & 81 \\
\hline Semantic $<\{$ orthographic and phonological $\}$ & $\begin{array}{l}\text { L. gyrus rectus } \\
\text { R. superior frontal gyrus } \\
\text { L. cerebellar hemisphere } \\
\text { R. superior frontal gyrus } \\
\text { Vermis } \\
\text { L. angular gyrus } \\
\text { L. cerebellar hemisphere } \\
\text { R. superior frontal gyrus } \\
\text { L. angular gyrus } \\
\text { R. superior frontal gyrus } \\
\text { R. superior frontal gyrus }\end{array}$ & $\begin{array}{r}6 \\
26 \\
-21 \\
9 \\
-1 \\
-50 \\
-45 \\
4 \\
-52 \\
23 \\
20\end{array}$ & $\begin{array}{r}52 \\
27 \\
-46 \\
22 \\
-48 \\
-62 \\
-69 \\
50 \\
-60 \\
31 \\
34\end{array}$ & $\begin{array}{r}-16 \\
50 \\
-27 \\
59 \\
-16 \\
23 \\
23 \\
14 \\
23 \\
50 \\
50\end{array}$ & $\begin{array}{r}1,466 \\
570 \\
407 \\
190 \\
136 \\
109 \\
81 \\
81 \\
54 \\
27 \\
27\end{array}$ \\
\hline Semantic $>\{$ orthographic and phonological $\}$ & $\begin{array}{l}\text { R. superior temporal gyrus } \\
\text { L. basal ganglia (putamen) } \\
\text { L. central gyrus } \\
\text { L. superior temporal gyrus } \\
\text { R. superior temporal gyrus } \\
\text { L. anterior cingulate gyrus } \\
\text { R. superior temporal gyrus } \\
\text { L. body of caudate } \\
\text { R. anterior cingulate gyrus } \\
\text { L. superior frontal gyrus } \\
\text { L. anterior cingulate gyrus } \\
\text { L. middle/superior temporal gyri } \\
\text { R. supramarginal gyrus } \\
\text { L. postcentral gyrus } \\
\text { L. insula } \\
\text { L. insula }\end{array}$ & $\begin{array}{r}55 \\
-25 \\
-60 \\
-45 \\
48 \\
-13 \\
47 \\
-21 \\
13 \\
-14 \\
-18 \\
-47 \\
35 \\
-42 \\
-37 \\
-26 \\
\end{array}$ & $\begin{array}{r}6 \\
8 \\
-1 \\
8 \\
-34 \\
20 \\
-21 \\
-13 \\
6 \\
-13 \\
4 \\
-28 \\
-34 \\
-22 \\
-1 \\
10 \\
\end{array}$ & $\begin{array}{r}5 \\
14 \\
23 \\
5 \\
14 \\
32 \\
5 \\
23 \\
32 \\
50 \\
32 \\
5 \\
23 \\
41 \\
14 \\
14 \\
\end{array}$ & $\begin{array}{r}3,638 \\
869 \\
760 \\
624 \\
597 \\
434 \\
326 \\
299 \\
271 \\
217 \\
190 \\
163 \\
109 \\
81 \\
54 \\
27 \\
\end{array}$ \\
\hline
\end{tabular}

core reading-related regions. Thus, as was hypothesized, the training that resulted in the least learning did not modulate activation in areas associated with increased reading efficiency.
Attention to phonological features. As compared with items trained orthographically or semantically, when items trained phonologically were subsequently named, relatively less activation was observed in the LH SMG, 

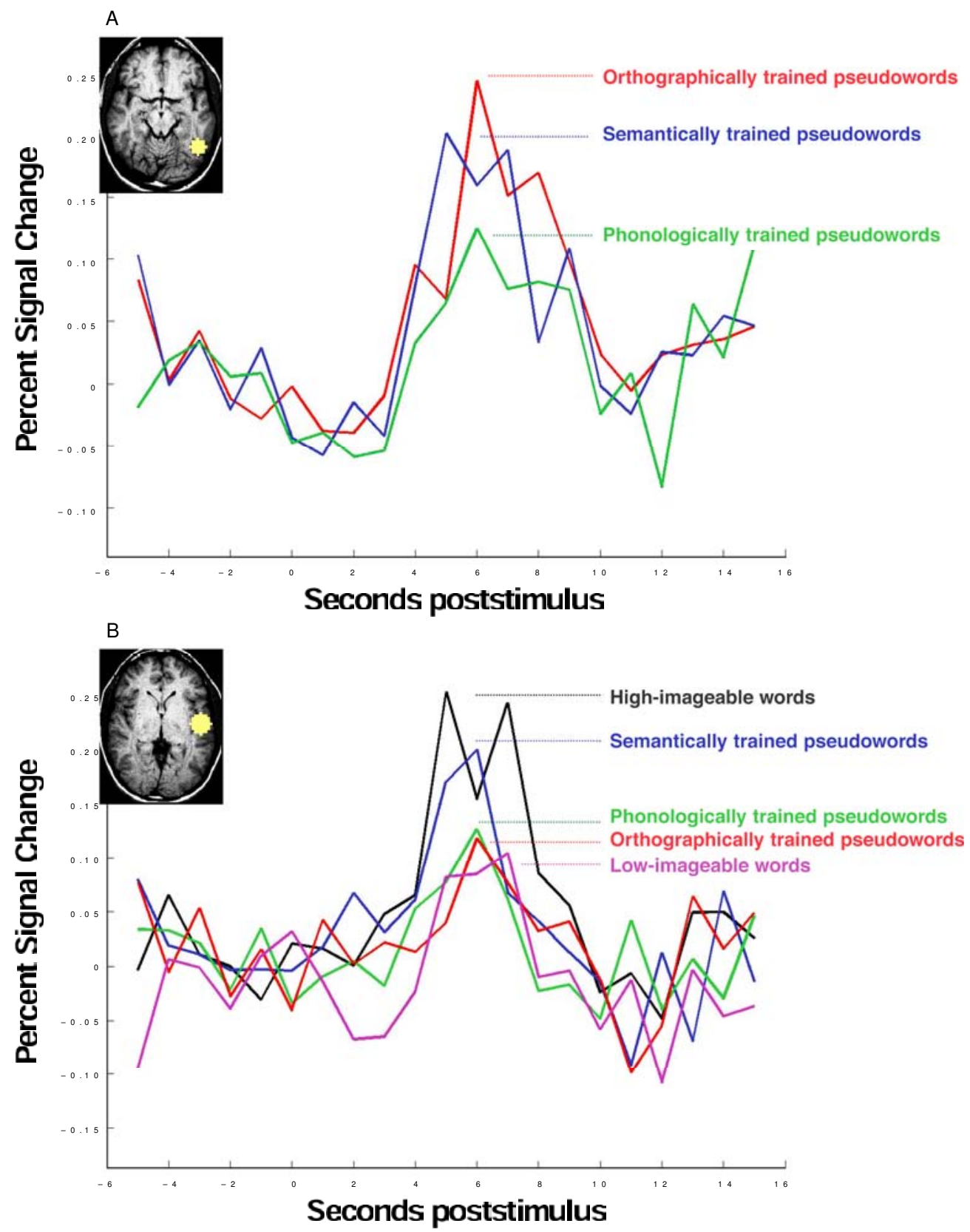

Figure 6. Region of Interest (ROI) analyses. (A) Time course of evoked activations for the left-hemisphere (LH) OT region. ROI is defined on the basis of Shaywitz et al. (2002), in which this region (center of mass: $x,-47 ; y,-52 ; z,-5)$ was maximally correlated with reading skill. (B) Time course of evoked activations for the $L H$ superior tem poral gyrus.

IFG, and OT regions. The pattern of engaged but relatively reduced activation in these three regions exactly replicates the pattern observed in our previous study of repetition-induced processing efficiency for real words (Katz et al., 2003). The present results are consistent with previous claims that the LH SMG, IFG, and OT regions are functionally linked and are involved in different aspects of phonological processing: phonological assem- bly (i.e., binding letters and letter clusters to their phonological representations), phonological recoding, and rapid retrieval of orthographic-to-phonological mappings, respectively (Katz et al., 2003; Mencl et al., 2002; Pugh, Mencl, Jenner, et al., 2000). In a recent study from our laboratory (Mencl et al., 2002), activation in all three of these regions was modulated by phonological priming. The processing of phonologically incongruous stimuli 
A

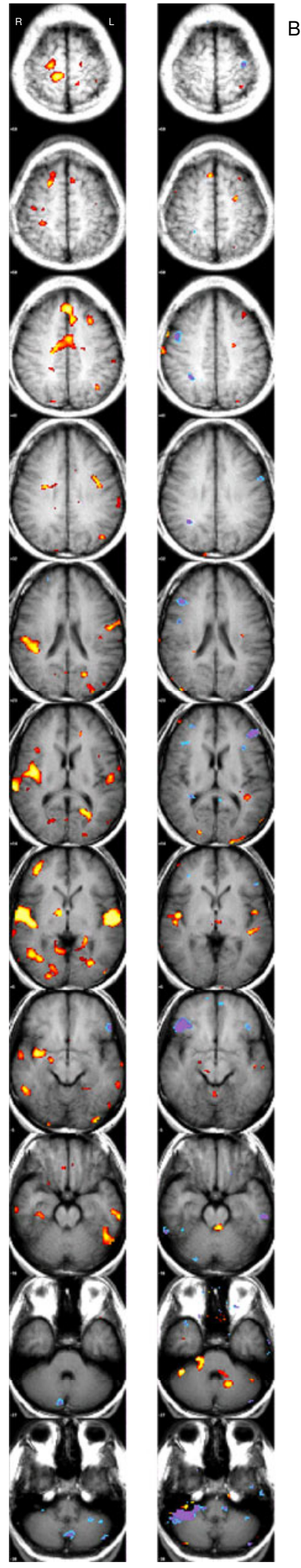

Figure 7. (A) Main effect of imageability: high- versus lowimageable words. (B) Regions in which evoked response to semantically trained pseudowords was correlated with how well the subjects had learned the "meanings" of those pseudowords. (e.g., COUCH-TOUCH) was associated with increased activation in the LH SMG, IFG, and OT region, whereas the processing of phonologically congruous stimuli (e.g., BRIBE-TRIBE) was associated with relatively less activation in these areas. The LH SMG and OT region are also functionally disrupted in dyslexic readers (Paulesu et al., 2001; Pugh, Mencl, Jenner, et al., 2000; Rumsey, Nace, et al., 1997; Salmelin et al., 1996; Shaywitz et al., 2002; Shay witz et al., 1998), whose core deficits are in phonological processing (Bradley \& Bryant, 1985; Liberman, Shankweiler, Liberman, Fowler, \& Fischer, 1977; Wagner $\&$ Torgesen, 1987), and as was noted, activation in the LH OT region has been shown to be directly related to reading skill in children (Shaywitz et al., 1998; Shaywitz et al., 2002). The fact that training that focused attention on the phonological features of pseudowords was associated with relatively less activation in these regions suggests that training facilitated the phonological assembly, phonological recoding, and rapid mapping of orthography to phonology required for naming and, hence, increased the efficiency of cortical regions normally associated with such processing.

Attention to semantic features. Despite behavioral gains that were nearly identical to those observed following phonological training, semantic training did not yield reduced activation in either the LH SMG or the IFG (critical in phonological assembly/recoding) nor in the OT region (critical in rapid fluent reading), relative to the phonological and orthographic training conditions. Relative to the other two training conditions, semantic training was associated primarily with greater activation in the bilateral STG and MTG extending anteriorly and inferiorly into the temporal pole. These results inform our understanding of the functional dissociations within the ventral system. In contrast to the posterior aspect of this system (the OT region, discussed above), the more anterior regions (including the LH STG and MTG, extending anteriorly into the temporal tip) seem to be involved in the semantic processing of words (see, e.g., Price et al., 1997; Rossell et al., 2003). In this study, reading pseudowords that had been associated with pictures during training engaged the same regions that showed heightened activation for concrete high-imageable words, relative to abstract low-imageable words, in this study. Together with the finding from our brain-behavior analysis that activation in the STG and the MTG was directly and positively related to how well the subjects had mastered semantic associations during training, these results suggest that semantic training resulted in the establishment and subsequent retrieval of semantic representations for the trained items. Thus, the subjects engaged the anterior aspects of the ventral system when they named pseudowords for which they had learned visually represented semantic associations and when they named real words with putatively strong visual-semantic representations.

This finding is also consistent with the results from our recent word repetition study (Katz et al., 2003), in which repetition was associated with decreased activation in the LH IFG, SMG, and OT region, but with 
Table 3

Direct Comparison of High- and Low-Imageable Words

\begin{tabular}{|c|c|c|c|c|c|c|}
\hline Contrast & Location & $x$ & $y$ & $z$ & Volume (mm) & $p$ Value (at Peak) \\
\hline High $>$ low imageable & $\begin{array}{l}\text { R. superior temporal gyrus } \\
\text { L. superior temporal gyrus } \\
\text { R. central gyrus } \\
\text { R. anterior cingulate gyrus } \\
\text { R. middle temporal gyrus } \\
\text { L. lingual gyrus } \\
\text { L. superior frontal gyrus } \\
\text { L. fusiform gyrus } \\
\text { R. lingual gyrus } \\
\text { R. insula } \\
\text { R. middle frontal gyrus } \\
\text { R. lingual gyrus } \\
\text { R. superior frontal sulcus } \\
\text { R. superior frontal gyrus } \\
\text { L. hippocampus } \\
\text { L. inferior temporal gyrus } \\
\text { L. inferior frontal gyrus } \\
\text { L. middle frontal gyrus } \\
\text { L. superior occipital gyrus } \\
\text { R. central gyrus } \\
\text { R. thalamus } \\
\text { R. parahippocampal gyrus } \\
\text { L. supramarginal gyrus } \\
\text { L. occipitotemporal gyrus } \\
\text { L. middle temporal gyrus } \\
\text { R. intraparietal sulcus } \\
\text { R. globus pallidus } \\
\text { L. angular gyrus } \\
\text { R. inferior frontal gyrus } \\
\text { L. supramarginal/angular gyri } \\
\text { R. inferior temporal gyrus }\end{array}$ & $\begin{array}{r}52 \\
-50 \\
13 \\
14 \\
42 \\
-18 \\
-1 \\
-45 \\
23 \\
35 \\
35 \\
13 \\
20 \\
21 \\
-21 \\
-60 \\
-37 \\
-26 \\
-30 \\
26 \\
11 \\
31 \\
-60 \\
-33 \\
-59 \\
30 \\
20 \\
-40 \\
35 \\
-35 \\
60\end{array}$ & $\begin{array}{r}-8 \\
-7 \\
-30 \\
-15 \\
-56 \\
-56 \\
31 \\
-50 \\
-83 \\
-4 \\
43 \\
-50 \\
-16 \\
10 \\
-36 \\
-24 \\
-4 \\
17 \\
-87 \\
-8 \\
-5 \\
-22 \\
-22 \\
-85 \\
-38 \\
-34 \\
-10 \\
-69 \\
17 \\
-62 \\
-16\end{array}$ & $\begin{array}{r}5 \\
5 \\
59 \\
41 \\
5 \\
14 \\
41 \\
-16 \\
5 \\
-5 \\
5 \\
5 \\
59 \\
50 \\
5 \\
-16 \\
32 \\
41 \\
23 \\
32 \\
5 \\
-16 \\
32 \\
-5 \\
-5 \\
50 \\
-5 \\
32 \\
14 \\
41 \\
-16\end{array}$ & $\begin{array}{r}11,836 \\
5,674 \\
3,230 \\
3,122 \\
2,823 \\
2,660 \\
2,660 \\
1,819 \\
1,792 \\
1,412 \\
1,303 \\
1,113 \\
1,032 \\
1,032 \\
923 \\
842 \\
842 \\
706 \\
679 \\
570 \\
570 \\
543 \\
461 \\
434 \\
407 \\
407 \\
380 \\
353 \\
326 \\
299 \\
271\end{array}$ & $\begin{array}{l}.0001 \\
.0015 \\
.0031 \\
.0113 \\
.0094 \\
.0072 \\
.0021 \\
.0104 \\
.0171 \\
.0047 \\
.0079 \\
.0193 \\
.0148 \\
.0122 \\
.0150 \\
.0106 \\
.0090 \\
.0181 \\
.0220 \\
.0108 \\
.0052 \\
.0239 \\
.0387 \\
.0152 \\
.0270 \\
.0221 \\
.0198 \\
.0167 \\
.0305 \\
.0177 \\
.0253\end{array}$ \\
\hline High $<$ low imageable & $\begin{array}{l}\text { L. cerebellar nuclei } \\
\text { L. inferior frontal gyrus } \\
\text { R. cerebellar hemisphere }\end{array}$ & $\begin{array}{r}-3 \\
-48 \\
8 \\
\end{array}$ & $\begin{array}{r}-67 \\
25 \\
-81\end{array}$ & $\begin{array}{r}-38 \\
-5 \\
-27\end{array}$ & $\begin{array}{l}706 \\
516 \\
434\end{array}$ & $\begin{array}{l}-.0111 \\
-.0107 \\
-.0208\end{array}$ \\
\hline
\end{tabular}

slightly increased activity in the MTG. The difference in the magnitude of activation in the MTG in these two studies (the semantically trained pseudowords in the present study were associated with greater MTG activation than were the repeated real words in Katz et al.'s, 2003, study) likely reflects a critical difference in stimulus properties: The heightened MTG activity in the present study probably reflects the fact that the semantic associations were recently learned and, as a result, were not accessed as efficiently as were the semantic representations of the repeated real words in Katz et al.'s (2003) study. The results from our brain-behavior analysis bolster this argument, since heightened activation in these same regions was associated with better encoding of the "meanings" of the semantically trained items.

Finally, we note that there were some regions that exhibited relatively less activation for semantically, as compared with orthographically and phonologically, trained items; particularly noteworthy is the LH angular gyrus. It is not obvious why activation in this region was relatively lower (more deactivated) for semantically trained items, although it is an intriguing effect, considering that this region has been associated with lexico-semantic processing and semantic retrieval (e.g., Price et al., 2003).
One might speculate that this reduced activation reflects increased efficiency in semantic retrieval. However, precisely how this reduction relates to the increased activation in anterior aspects of the ventral system (the STG and the MTG) is not clear. Given the importance of the angular gyrus in reading and dyslexia (Dejerine, 1891; Horwitz, Rumsey, \& Donohue, 1998), future studies should continue to investigate both its function during reading and learning and its relation to other regions associated with semantic processing.

\section{Toward a Theory of the Neural Basis of Word Learning}

It is particularly striking that despite nearly equivalent behavioral transfer from the phonological and the semantic training conditions, clearly distinct cortical activation patterns were observed when items trained in these conditions were later named aloud. Especially noteworthy is the fact that only phonological training was associated with reduced activation (increased processing efficiency) in the OT region. This strongly suggests that comparable learning (indexed as facilitated word naming) was achieved via different underlying processes. On a methodological note, the dissociation 
Table 4

Brain-Behavior Correlations (Relationship Between Evoked Responses to Semantically Trained Items and Accuracy During Semantic Training)

\begin{tabular}{|c|c|c|c|c|c|c|}
\hline Relationship & Location & $x$ & $y$ & $z$ & Volume $(\mathrm{mm})$ & $p$ Value (at Peak) \\
\hline \multirow[t]{11}{*}{ Positive correlations } & R. superior temporal gyrus & 43 & -8 & 5 & 1,303 & .0290 \\
\hline & L. cerebellar nuclei & -16 & -58 & -27 & 787 & .0259 \\
\hline & L. superior temporal gyrus & -40 & -26 & 5 & 652 & .0296 \\
\hline & L. middle occipital gyrus & -20 & -97 & 14 & 570 & .0302 \\
\hline & R. cerebellar hemisphere & 40 & -40 & -27 & 516 & .0181 \\
\hline & L. superior temporal gyrus & -38 & -38 & 14 & 489 & .0340 \\
\hline & L. middle frontal/precentral gyri & -23 & -7 & 50 & 489 & .0306 \\
\hline & L. superior temporal gyrus & -47 & -5 & 5 & 353 & .0286 \\
\hline & R. superior frontal gyrus & 6 & 20 & 50 & 326 & .0270 \\
\hline & L. middle frontal gyrus & -33 & 24 & 41 & 299 & .0445 \\
\hline & Vermis & 1 & -52 & -5 & 271 & .0390 \\
\hline \multirow[t]{13}{*}{ Negative correlations } & R. cerebellar hemisphere & 31 & -42 & -38 & 3,882 & .0151 \\
\hline & R. inferior frontal gyrus & 42 & 25 & -5 & 2,362 & .0168 \\
\hline & L. inferior frontal gyrus & -42 & 34 & 14 & 1,004 & .0155 \\
\hline & R. inferior frontal gyrus & 40 & 24 & 23 & 977 & .0328 \\
\hline & R. middle frontal/precentral gyri & 45 & -1 & 41 & 787 & .0281 \\
\hline & R. supramarginal gyrus & 31 & -50 & 32 & 706 & .0236 \\
\hline & L. inferior temporal gyrus & -55 & -24 & -16 & 489 & .0133 \\
\hline & L. superior occipital/angular gyri & -42 & -81 & 23 & 407 & .0203 \\
\hline & L. precentral gyrus & -31 & -16 & 59 & 380 & .0283 \\
\hline & R. inferior temporal gyrus & 59 & -46 & -16 & 353 & .0305 \\
\hline & L. inferior frontal gyrus & -52 & 1 & 32 & 326 & .0379 \\
\hline & L. inferior frontal gyrus & -38 & 25 & -5 & 326 & .0364 \\
\hline & R. inferior frontal/precentral gyri & 43 & 1 & 23 & 271 & .0293 \\
\hline
\end{tabular}

between the behavioral and the neurobiological effects of phonological and semantic training illustrates the utility of examining these two levels of analysis.

As has already been discussed, we speculate that the reduced SMG, IFG, and OT region activation associated with phonological training reflects more efficient phonological processing. In contrast, we suspect that the increased anterior ventral activation associated with semantic training reflects the establishment and/or retrieval of semantic representations. Thus, although the results from the present study are generally consistent with our initial model (Pugh, Mencl, Jenner, et al., 2000), the functional dissociations that we observed within the ventral system suggest that our initial conception of the dorsal and ventral systems merits revisiting and refinement. In the following sections, we will consider (1) how the OT region becomes specialized for reading and (2) the role of the more anterior ventral areas in the development of efficient word reading.

Training of the OT region. The fact that relative to phonological training, neither orthographic training (which focused attention on the consonant/vowel status of the individual letters in the pseudowords) nor semantic training (which encouraged the association of novel lexical items with visually represented semantic information) modulated activation in the OT region is consistent with recent assertions that this region (1) is sensitive to learned language-specific orthographic regularities, (2) does not depend exclusively on the letter-level visual features of stimuli (L. Cohen et al., 2002), and (3) is involved in presemantic, "prelexical" processing (De- haene, Le Clec'H, Poline, Le Bihan, \& Cohen, 2002). On the other hand, the fact that attention to phonological features during training was associated with relatively reduced activation (increased efficiency) in this region calls into question the putatively visual nature of this skill region. Critically, these results instead imply that the OT region is involved in the mapping of orthography to phonology (Xu et al., 2001), suggesting that attention to these relations is required for the tuning of the OT region and, in turn, the development of efficient fluent word reading. From this, it follows that phonological analysis and assembly (processes most strongly associated with dorsal regions) are central in the early stages of learning to read new words efficiently.

On the basis of this conclusion, we postulate that initial processing within the dorsal system contributes to the specialization of the ventral system. As has been reviewed, phonologicalprocessing engages regions within the dorsal system; these regions predominate early in reading acquisition and during the processing of unfamiliar words. Moreover, in the present study, reduced activation (increased efficiency) in the OT region was evident only when reduced activation was concurrently observed in the dorsal and anterior regions. It appears that both the dorsal and the ventral systems depend on the extraction of phonological information from print in order to recognize written words (Pugh, Mencl, Jenner, et al., 2000). We hypothesize that the functioning of the OT region is derived from that of the dorsal system. Evidence suggests that the dorsal system must be intact for the ventral system to develop. For example, Shaywitz et al. (2002) found that 
in developing readers, engagement of the dorsal system developmentally precedes specialization of the ventral system for reading. Previous neuroimaging studies have also shown that dyslexic readers fail to activate both $\mathrm{LH}$ dorsal and ventral regions (Paulesu et al., 2001; Salmelin et al., 1996; Shaywitz et al., 1998; Shaywitz et al., 2002; Simos, Breier, Fletcher, Bergman, \& Papanicolaou, 2000), and several studies have converged on the finding that gains in reading skill resulting from successful reading intervention are associated with a more "normalized" localization of reading processes in the brain, with increased activation in both the LH dorsal and the LH posterior ventral regions (Shaywitz, Shaywitz, Blachman, et al., 2003; Simos, Fletcher, et al., 2002; Temple et al., 2003).

The role of the anterior ventral regions in learning. Under the experimental conditions within the present study, semantic processing during learning did not increase the efficiency of the OT region. This finding may be surprising given that (1) semantically trained items were named as quickly as phonologically trained items and (2) ecologically, an important goal of reading is the rapid and fluent access of semantic, in addition to phonological, representations. In keeping with this, we point out that another neurobiological hallmark of skilled word reading, specifically tied to the access of semantic information during word reading, appears to be modulation of activity in anterior aspects of the ventral system, including the MTG, extending into the temporal tip and the basal surface of the temporal lobe (Price et al., 1997; Rossell et al., 2003). In fact, semantic training in the present study was associated with markedly increased activation in some of these anterior ventral regions. As was noted earlier, we speculate that this enhanced activation reflects the establishment and subsequent retrieval of semantic representations for trained items. We further speculate that these semantic representations underlie the observed behavioral advantage (indexed by naming latency) for semantically trained items relative to orthographically trained items. However, rather than enhancing fluency by increasing the efficiency of the OT region, the semantic training appears to have allowed semantic information to supplement phonological assembly. This suggestion is consistent with behavioral findings (Strain, Patterson, \& Seidenberg, 1995) that a word's semantic characteristics can exert an influence on the computation of phonological representations and, in turn, the facility with which that word is named aloud. Strain et al. found that exception words (with irregular spelling-to-sound correspondences), which normally exhibit a latency disadvantage, did not show such disadvantages if their meanings were highly imageable. This finding demonstrates that semantic information can exert an influence on the efficiency with which a word is named. However, because this influence did not appear to increase the efficiency of the OT region in the present study, we maintain that semantic information processing is secondary to phonological information processing in the early stages of learning and in the specialization of this skill-related region. Of course, it is possible that with more repetitions (and experience), semantic training might have resulted in increased efficiency in the OT region.

Finally, we point out that the functional dissociation between posterior and anterior aspects of the ventral system observed in this study is consistent with recent findings suggesting that if one moves anteriorly through this system, subregions respond to word and word-like stimuli in a progressively abstracted and linguistic manner (Tarkiainen, Cornelissen, \& Salmelin, 2002). Very early in processing, the most posterior aspects of this system (i.e., extrastriate components) respond indiscriminately to any type of letter string (Tarkiainen et al., 2002); subsequently, the OT region shows a heightened response to pseudowords relative to words (in addition, both words and pseudowords show heightened activation relative to nonpronounceable consonant strings in this region; L. Cohen et al., 2002); and, at later stages of processing, the more anterior aspects of the ventral system (MTG/ITG) show a heightened response to real words relative to other types of letter strings (Fiebach et al., 2002; Simos, Breier, et al., 2002; Tagamets et al., 2000).

\section{Implications and Future Directions}

The finding that only training that required explicit attention to the phonological features of novel words resulted in the most efficient processing (least activation) in the LH OT region suggests that to optimize learning (ultimately increasing the efficiency of the OT region), initial and remedial reading instruction must engage dorsal regions by explicitly drawing attention to the phonological properties of words. It should be noted that whereas the semantic training condition did not explicitly require phonological processing, it is nevertheless likely that the subjects engaged in some form of implicit phonological processing during semantic training (Van Orden, 1987; see Carello, Turvey, \& Lukatela, 1992 for a similar argument). Nevertheless, whatever minimal/implicit phonological processing took place as the subjects learned semantic associations during semantic training was not sufficient to increase efficiency in the OT region under these experimental conditions.

Such minimal phonological processing during visual word recognition is akin to the way that dyslexic readers process written words. As was noted earlier, the core deficit in the majority of dyslexic readers is in phonological processing. This behavioral marker is usually accompanied by an increased functional role for $\mathrm{RH}$ posterior and bihemispheric IFG sites (e.g., Pugh, Mencl, Shaywitz, et al., 2000; Shaywitz et al., 1998). It is possible that dyslexic readers disproportionately engage inferior frontal sites because of an increased reliance on covert pronunciation (phonological recoding) in an attempt to cope with deficient phonological analysis skills. In addition, their greater activation of the posterior RH with reduced $\mathrm{LH}$ posterior activation suggests a process of word recognition that accesses $\mathrm{RH}$-localized visuosemantic representations rather than relying on phonologically 
structured word recognition strategies. The present findings demonstrate that even for skilled readers, attempting to read new words in such a phonologically devoid manner will not result in increased efficiency of the OT region; attending to the orthographic or semantic features, without also attending to phonological features, does not seem to be sufficient for the training of this important skill area. Considered in this context, the results from the present study are consistent with the finding that explicit instruction of phonics (i.e., letter-sound correspondences) and analytic decoding strategies results in larger gains in reading skill than do more holistic (semantically focused) and implicit phonics instruction strategies (cf. Adams, 1994; Foorman, Francis, Fletcher, Schatschneider, \& Mehta, 1998).

Given that (1) both the phonological and the semantic training conditions resulted in facilitated naming times, (2) phonological training maximally increased efficiency in the dorsal, anterior, and posterior aspect (OT) of the ventral systems, (3) the semantic training maximally engaged anterior ventral regions (the STG and the MTG), and (4) efficient processing in all of these areas has been associated with skilled reading, it might follow that the best learning (in the context of reading) may entail the development of more efficient phonological processing and also the strengthening of semantic representations. This speculation is congruent with behavioral findings from research on reading instruction: Reviews of instructional practice have concluded that rich integrated curricula that combine emphases on phonological decoding and also "reading for meaning" lead to the best reading outcomes (Adams, 1994; National Reading Panel, 2000). Accordingly, in the context of the type of experimental manipulation employed in the present study, one might speculate that training that emphasizes attending to both phonological and semantic features will result in even better learning than will either phonological or semantic training alone. In a recent behavioral pilot study, we found that a training protocol that focused attention on both phonological and semantic features resulted in speeded naming times, relative to two other training conditions in which attention was focused on $e i$ ther phonological or semantic features (with number of exposures during training held constant between training conditions). A follow-up functional imaging study is currently underway to examine the effects of this combined training on the cortical regions recruited for the naming of learned items.

\section{Summary and Conclusions}

In this study, we examined the behavioral and neurobiological effects when a group of skilled readers attended to orthographic, phonological, and semantic features as they acquired familiarity for a set of novel words. Of the three conditions, only phonological training was associated with both facilitated naming and the pattern of cortical activations characteristic of increasingly efficient word recognition. Of particular importance is the finding that only the phonological training condition resulted in increased efficiency in the LH OT region, which has been shown to be critical in skilled reading. Thus, the interpretation of the learning (assessed behaviorally) seen for the phonologically encoded items in the present study seems straightforward: Learning was facilitated when phonological processing was engaged in during training; this, in turn, resulted in efficient phonological processing (instantiated cortically as relatively reduced activation in the IFG and the SMG) and efficient retrieval of presemantic lexical representations during subsequent naming (instantiated cortically as relatively reduced activation in the OT region). The semantic training condition also facilitated naming but was associated with increased activation in areas previously implicated in semantic processing, suggesting that the establishment and retrieval of semantic representations compensated for less efficient phonological processing for these items. These findings extend our understanding of how the OT region is tuned: Not only is this region sensitive to language-specific orthographic information and regularities (L. Cohen et al., 2002), but also it is sensitive to the phonological structure of words (Katz et al., 2003; Mencl et al., 2002; Pugh, Mencl, Jenner, et al., 2000; Pugh et al., 1997; Xu et al., 2001). Phonologically analytic processing seems to contribute to the specialization of this region. Therefore, the function of this putative VWFA extends beyond the rapid retrieval of the visual word form to the rapid mapping of the visual to the phonological word form (see also Xu et al., 2001). Future investigations of the functional roles of these regions in reading and learning to read will further inform our model of the functional neuroanatomy of reading, ultimately allowing for a more precise specification of how the system as a whole is organized and operates.

\section{REFERENCES}

ADAMS, M. J. (1994). Beginning to read: Thinking and learning about print. Cambridge, MA: MIT Press.

Balota, D. A., \& Chumbley, J. I. (1984). Are lexical decisions a good measure of lexical access? The role of word frequency in the neglected decision stage. Journal of Experimental Psychology: Human Perception \& Performance, 10, 340-357.

BENSON, D. F. (1994). The neurology of thinking. New York: Oxford University Press.

BLACK, S. E., \& Behrmann, M. (1994). Localization in alexia. In A. Kertesz (Ed.), Localization and neuroimaging in neuropsychology (pp. 331-376). New York: Academic Press.

Booth, J. R., Burman, D. D., Van Santen, F., Harasaki, Y., Gitelman, D. R., PARrish, T. B., \& Mesulam, M. M. (2001). The development of specialized brain systems in reading and oral-language. Child Neuropsychology, 7, 119-141.

BRADLEY, L., \& BRYANT, P. (1985). Rhyme and reason in reading and spelling. Ann Arbor: University of Michigan Press.

Breier, J. I., Simos, P. G., Zouridakis, G., \& PAPanicolaou, A. C. (1998). Relative timing of neuronal activity in distinct temporal lobe areas during a recognition memory task for words. Journal of Clinical \& Experimental Neuropsychology, 20, 782-790.

Brunswick, N., McCrory, E., Price, C. J., Frith, C. D., \& Frith, U. (1999). Explicit and implicit processing of words and pseudowords by adult developmental dyslexics: A search for Wernicke's Wortschatz? Brain, 122, 1901-1917. 
Carello, C., Turvey, M. T., \& Lukatela, G. (1992). Can theories of word recognition remain stubbornly nonphonological? In R. Frost \& L. Katz (Eds.), Orthography, phonology, morphology, and meaning: Advances in psychology (Vol. 94, pp. 211-226). Amsterdam: NorthHolland.

Clark, D., \& WAgner, A. D. (2003). Assembling and encoding word representations: fMRI subsequent memory effects implicate a role for phonological control. Neuropsychologia, 41, 304-317.

Cohen, J. D., MacWhinney, B., Flatt, M., \& Provost, J. (1993). PsyScope: An interactive graphic system for designing and controlling experiments in the psychology laboratory using Macintosh computers. Behavior Research Methods, Instruments, \& Computers, 25, 257-271.

Cohen, L., Dehaene, S., Naccache, L., Lehericy, S., DehaeneLambertz, G., HenafF, M. A., \& Michel, F. (2000). The visual word form area: Spatial and temporal characterization of an initial stage of reading in normal subjects and posterior split-brain patients. Brain, 123, 291-307.

Cohen, L., Lehericy, S., Chochon, F., Lemer, C., Rivaud, S., \& DeHAENE, S. (2002). Language-specific tuning of visual cortex? Functional properties of the visual word form area. Brain, 125, 1054-1069.

Coltheart, M., Curtis, B., Atkins, P., \& Haller, M. (1993). Models of reading aloud: Dual-route and parallel-distributed-processing approaches. Psychological Review, 100, 589-608.

Coltheart, M., DavelaAr, E., JonAsson, J. T., \& Besner, D. (1977). Access to the internal lexicon. In S. Dornic (Ed.), Attention and performance VI (pp. 535-555). London: Academic Press.

Coull, J. (1998). Neural correlates of attention and arousal insights from electrophysiology, functional neuroimaging and psychopharmacology. Progress in Neurobiology, 55, 343-361.

Dale, A. M., Liu, A. K., Fischl, B. R., Buckner, R. L., Belliveau, J. W., Lewine, J. D., \& Halgren, E. (2000). Dynamic statistical parametric mapping: Combining fMRI and MEG for high-resolution imaging of cortical activity. Neuron, 26, 55-67.

Dehaene, S., Le Clec'H, G., Poline, J.-B., Le Bihan, D., \& Cohen, L. (2002). The visual word form area: A prelexical representation of visual words in the fusiform gyrus. NeuroReport, 13, 321-325.

DEJERINE, J. (1891). Sur un cas de cecité verbale avec agraphie, suivi d'autopsie. Memoires de la Societé de Biologie, 4, 61-90.

Fiebach, C. J., Friederici, A. D., Müller, K., \& von Cramon, D. Y. (2002). f MRI evidence for dual routes to the mental lexicon in visual word recognition. Journal of Cognitive Neuroscience, 14, 11-23.

Fiez, J. A., Balota, D. A., Raichle, M. E., \& Petersen, S. E. (1999). Effects of lexicality, frequency, and spelling-to-sound consistency on the functional anatomy of reading. Neuron, 24, 205-218.

FieZ, J. A., \& Petersen, S. E. (1998). Neuroimaging studies of word reading. Proceedings of the National Academy of Sciences, 95, 914921.

Foorman, B. R., Francis, D. J., Fle tCher, J. M., SChatschneider,C., \& MentA, P. (1998). The role of instruction in learning to read: Preventing reading failure in at-risk children. Journal of Educational Psychology, 90, 37-55.

Friston, K. J., Ashburner, J., Frith, C. D., Poline, J.-B., Heather, J. D., \& FRACKOWIAK, R. S. J. (1995). Spatial registration and normalization of images. Human Brain Mapping, 2, 165-189.

Friston, K. J., Holmes, A. P., \& Worsley, K. J. (1999). How many subjects constitute a study? NeuroImage, 10, 1-5.

GESCHWIND, N. (1965a). Disconnexion syndromes in animals and man: Pt. I. Brain, 88, 237-294.

GESCHWIND, N. (1965b). Disconnexion syndromes in animals and man: Pt. II. Brain, 88, 585-644.

Gilhooly, K. J., \& LogIE, R. H. (1980). Age-of-acquisition, imagery, concreteness, familiarity, and ambiguity measures for 1,944 words. Behavior Research Methods \& Instrumentation, 12, 395-427.

HARM, M. W., \& SEIDENBERG, M. S. (1999). Computing the meanings of words in reading: Cooperative division of labor between visual and phonological processes. Psychological Review, 106, 491-528.

Helenius, P., Tarkiainen, A., Cornelissen, P., Hansen, P. C., \& SALMELIN, R. (1999). Dissociation of normal feature analysis and de- ficient processing of letter-strings in dyslexic adults. Cerebral Cortex, 9, 476-483.

Holmes, A. P., \& Friston, K. J. (1998). Generalizability, random effects, and population inference [Abstract]. NeuroImage, 7, S34.

Horwitz, B., Rumsey, J. M., \& Donohue, B. C. (1998). Functional connectivity of the angular gyrus in normal reading and dyslexia. Proceedings of the National Academy of Sciences, 95, 8939-8944.

JARED, D. (1997). Evidence that strategy effects in word naming reflect changes in output timing rather than changes in processing route. Journal of Experimental Psychology: Learning, Memory, \& Cognition, 23, 1424-1438.

Jose PHS, O., TURnER, R., \& Friston, K. [J.] (1997). Event-related fMRI. Human Brain Mapping, 5, 243-248.

Katz, L., Lee, C., Frost, S. J., Mencl, W. E., Rueckl, J. G., SANDAK, R., TABOR, W., MASON, S., \& PUGH, K. R. (2003). Effects of printed word repetition in lexical decision and naming on behavior and brain activation. Manuscript submitted for publication.

KIRK, R. E. (1982). Experimental design: Procedures for the social sciences. Belmont, CA: Wadsworth.

KUČERA,H., \& FRANCIS, W. N. (1967). Computationalanalysis of presentday American English. Providence, RI: Brown University Press.

Liberman, I. Y., Shankweiler, D., Liberman, A. M., Fowler, C., \& FISCHER, F. W. (1977). Phonetic segmentation and recoding in the beginning reader. In A. S. Reber \& D. L. Scarborough (Eds.), Toward a psychology of reading (pp. 207-225). Hillsdale, NJ: Erlbaum.

Mencl, W. E., Frost, S. J., Sandak, R., Mason, S., Lee, J. R., Rueckl, J. G., Constable, T., Katz, L., Pugh, K., \& Gore, J. C. (2002, June). Effects of orthographic and phonologic priming during lexical decision: An fMRI study. Poster presented at the 8th International Conference on Functional Mapping of the Human Brain, Sendai.

Miezin, F. M., Maccotta, L., Ollinger, J. M., Petersen, S. E., \& BUCKNER, R. L. (2000). Characterizing the hemodynamic response: Effects of presentation rate, sampling procedure, and the possibility of ordering brain activity based on relative timing. NeuroImage, 11, 735-759.

National Reading Panel (2000). Teaching children to read: An evidence-based assessment of the scientific research literature on reading and its implications for reading instruction. Washington, DC: National Institute of Child Health and Human Development.

Paivio, A., Yuille, J. C., \& Madigan, S. A. (1968). Concreteness, imagery, and meaningfulness values for 925 nouns. Journal of Experimental Psychology Monograph Supplement, 76(3, Pt. 2), 1-25.

Paulesu, E., Demonet, J.-F., Fazio, F., McCrory, E., Chanoine, V., Brunswick, N., CAPPA, S. F., Cossu, G., Habib, M., Frith, C. D., \& Frith, U. (2001). Dyslexia: Cultural diversity and biological unity. Science, 291, 2165-2167.

Paulesu, E., Frith, C. D., \& Frackowiak, R. S. J. (1993). The neural correlates of the verbal component of working memory. Nature, $\mathbf{3 6 2}$, 342-345.

Poldrack, R. A., \& GABRIELI, J. D. E. (2001). Characterizing the neural mechanisms of skill learning and repetition priming: Evidence from mirror reading. Brain, 124, 67-82.

Poldrack, R. A., Selco, S. L., Field, J. E., \& Cohen, N. J. (1999). The relationship between skill learning and repetition priming: Experimental and computational analyses. Journal of Experimental Psychology: Learning, Memory, \& Cognition, 25, 208-235.

Posner, M., \& Dehaene, S. (1994). Attentional networks. Trends in Neurosciences, 17, 75-79.

Price, C. J., Moore, C. J., Humphreys, G. W., \& Wise, R. J. S. (1997). Segregating semantic from phonological processes during reading. Journal of Cognitive Neuroscience, 9, 727-733.

Price, C. J., Winterburn, D., Giraud, A. L., Moore, C. J., \& NopPENEY, U. (2003). Cortical localisation of the visual and auditory word form areas: A reconsideration of the evidence. Brain \& Language, 86, 272-286.

Price, C. J., Wise, R. J. S., \& Frackowiak, R. S. J. (1996). Demonstrating the implicit processing of visually presented words and pseudowords. Cerebral Cortex, 6, 62-70.

Pugh, K. R., Mencl, W. E., Jenner, A. R., Katz, L., Frost, S. J., Lee, 
J. R., Shaywitz, S. E., \& Shaywitz, B. A. (2000). Functional neuroimaging studies of reading and reading disability (developmental dyslexia). Mental Retardation \& Developmental Disabilities Research Reviews, 6, 207-213.

Pugh, K., Mencl, E. W., Shaywitz, B. A., Shaywitz, S. E., FulBRight, R. K., Skudlarski, P., Constable, R. T., Marchione, K., Jenner, A. R., Shankweiler, D. P., Katz, L., Fletcher, J., LACADIE, C., \& GORE, J. C. (2000). The angular gyrus in developmental dyslexia: Task-specific differences in functional connectivity in posterior cortex. Psychological Science, 11, 51-56.

Pugh, K. R., Shaywitz, B. A., Shaywitz, S. A., Shankweiler, D. P., Katz, L., Fletcher, J. M., Skudlarski, P., Fulbright, R. K., CONStable, R. T., Bronen, R. A., LACAdie, C., \& Gore, J. C. (1997). Predicting reading performance from neuroimaging profiles: The cerebral basis of phonological effects in printed word identification. Journal of Experimental Psychology: Human Perception \& Performance, 2, 1-20.

RATCLIFF, R. (1978). A theory of memory retrieval. Psychological Review, 85, 59-108.

Rossell, S. L., Price, C. J., \& Nobre, A. C. (2003). The anatomy and time course of semantic priming investigated by fMRI and ERPs. Neuropsychologia, 41, 550-564.

Rumsey, J. M., Horwitz, B., Donohue, B. C., NAce, K., Maisog, J. M., \& ANDREASON, P. (1997). Phonological and orthographic components of word recognition: A PET-rCBF study. Brain, 120, 739-759.

Rumsey, J. M., Nace, K., Donohue, B., Wise, D., Maisog, J. M., \& ANDREASON, P. (1997). A positron emission tomographic study of impaired word recognition and phonological processing in dyslexic men. Archives of Neurology, 54, 562-573.

Salmelin, R., Service, E., Kiesila, P., Uutela, K., \& Salonen, O. (1996). Impaired visual word processing in dyslexia revealed with magnetoencephalography. Annals of Neurology, 40, 157-162.

Seidenberg, M. S., WATERS, G. S., BARnes, M. A., \& TANEnhaus, M. K. (1984). When does irregular spelling or pronunciation influence word recognition? Journal of Verbal Learning \& Verbal Behavior, 23, 383-404.

Shaywitz, B. A., Shaywitz, S. E., Blachman, B., Pugh, K. R., FulBRight, R. K., SkUdlarski, P., MenCl, W. E., Constable, R. T., HoLAhan, J. M., MARChiOne, K. E., Fletcher, J. M., Lyon, G. R., \& GORE, J. C. (2003, June). Development of left occipito-temporal systems for skilled reading following a phonologically-based intervention in children. Poster presented at the 9th International Conference on Functional Mapping of the Human Brain, New York.

Shaywitz, S. E., ShaYwitz, B. A., Fulbright, R. K., Skudlarski, P., Mencl, W. E., Constable, R. T., Pugh, K. R., Holahan, J. M., Marchione, K. E., Fletcher, J. M., Lyon, G. R., \& Gore, J. C. (2002). Neural systems for compensation and persistence: Young adult outcome of childhood reading disability. Biological Psychiatry, 52, 101-110.

Shaywitz, S. E., Shaywitz, B. A., Fulbright, R. K., Skudlarski, P., Mencl, W. E., Constable, R. T., Pugh, K. R., Holahan, J. M., Marchione, K. E., Fletcher, J. M., Lyon, G. R., \& Gore, J. C. (2003). Neural systems for compensation and persistence: Young adult outcome of childhood reading disability. Biological Psychiatry, 54, 25-33.

Shaywitz, S. E., Shaywitz, B. A., Pugh, K. R., Fulbright, R. K., Constable, R. T., Mencl, W. E., Shankweiler, D. P., Liberman, A. M., SKudlarski, P., Fletcher, J. M., Katz, L., Marchione, K. E., Lacadie, C., Gatenby, C., \& Gore, J. C. (1998). Functional disruption in the organization of the brain for reading in dyslexia. Proceedings of the National Academy of Sciences, 95, 2636-2641.

Simos, P. G., Breier, J. I., Fletcher, J. M., Bergman, E., \& PapaniCOLAOU, A. C. (2000). Cerebral mechanisms involved in word reading in dyslexic children: A magnetic source imaging approach. Cerebral Cortex, 10, 809-816.

Simos, P. G., Breier, J. I., Fletcher, J. M., Foorman, B. R., CAstillo, E. M., \& PAPANicolaou, A. C. (2002). Brain mechanisms for reading words and pseudowords: An integrated approach. Cerebral Cortex, 12, 297-305.

Simos, P. G., Fletcher, J. M., Bergman, E., Breier, J. I., Foorman,
B. R., Castillo, E. M., Davis, R. N., Fitzgerald, M., \& PapaniCOLAOU, A. C. (2002). Dyslexia-specific brain activation profile becomes normal following successful remedial training. Neurology, $\mathbf{5 8}$, 1203-1213.

Strain, E., Patterson, K., \& Seidenberg, M. S. (1995). Semantic effects in single-word naming. Journal of Experimental Psychology: Learning, Memory, \& Cognition, 21, 1140-1154.

TAgamets, M. A., Novick, J. M., Chalmers, M. L., \& Friedman, R. B. (2000). A parametric approach of orthographic processing in the brain: An fMRI study. Journal of Cognitive Neuroscience, 12, 281-297.

TALAIRACH, J., \& TOURNOUX, P. (1988). Coplanar stereotactic atlas of the human brain. Three-dimensional proportional system: An approach to cerebral imaging. New York: Thieme Medical.

Tarkiainen, A., Cornelissen, P. L., \& Salmelin, R. (2002). Dynamics of visual feature analysis and object-level processing in face versus letter-string perception. Brain, 125, 1125-1136.

Tarkiainen, A., Helenius, P., Hansen, P. C., Cornelissen, P. L., \& SAlMElin, R. (1999). Dynamics of letter string perception in the human occipitotemporal cortex. Brain, 122, 2119-2132.

Temple, E., Deutsch, G. K., Poldrack, R. A., Miller, S. L., TalLAL, P., Merzenich, M. M., \& GABrieli, J. D. E. (2003). Neural deficits in children with dyslexia ameliorated by behavioral remediation: Evidence from functional MRI. Proceedings of the National Academy of Sciences, 100, 2860-2865.

Toglia, M. P., \& BATTIG, W. R. (1978). Handbook of semantic word norms. New York: Erlbaum.

Turkeltaub, P. E., Gareau, L., Flowers, D. L., Zeffiro, T. A., \& EDEN, G. F. (2003). Development of neural mechanisms for reading. Nature Neuroscience, 6, 767-773.

VAN ORDEN, G. C. (1987). A ROWS is a ROSE: Spelling, sound, and reading. Memory \& Cognition, 15, 181-198.

Van Orden, G. C., Pennington, B. F., \& Stone, G. O. (1990). Word identification in reading and the promise of subsymbolic psycholinguistics. Psychological Review, 97, 488-522.

WAGNER, R. K., \& TORGESEN, J. K. (1987). The nature of phonological processing and its causal role in the acquisition of reading skills. Psychological Bulletin, 101, 192-212.

WATE Rs, G. S., Seidenberg. M. S., \& Bruck, M. (1985). Children's and adult's use of spelling-sound information in three reading tasks. Memory \& Cognition, 12, 293-305.

Woods, R. P. (1996). Modeling for intergroup comparisons of imaging data. NeuroImage, 4, S84-S94.

Xu, B., Grafman, J., Gaillard, W. D., Ishit, K., Vega-Bermude Z,F., Pietrini, P., Reeves-Tyer, P., DiCamillo, P., \& Theodore, W. (2001). Conjoint and extended neural networks for the computation of speech codes: The neural basis of selective impairment in reading words and pseudowords. Cerebral Cortex, 11, 267-277.

\section{NOTES}

1. RT data were not recorded for 1 subject, due to equipment failure. 2 . This difference was driven by a reliable training condition $\times$ group interaction $[F(4,66)=16.65, p<.001]$, such that during semantic training, the MRI cohort $(M=0.83)$ outperformed the pilot cohort $(M=0.73)$. Planned comparisons revealed that the two cohorts did not differ in accuracy during orthographic or phonological training (at any exposure).

3 . The ANOVA on RT revealed a reliable exposure $\times$ group interaction $[F(7,224)=3.27, p<.01]$, so that the MRI cohort was slightly faster than the pilot cohort on the last three exposures. These effects are orthogonal to our contrasts of interest and do not compromise our justification in using the naming RT data from the pilot group as an estimate for the behavior of the MRI group.

4. RT data were not recorded for 1 subject, due to equipment failure.

5. Because we observed a slight difference in accuracy during semantic training between the pilot and the fMRI cohorts (described earlier), we conducted a post hoc analysis in which we examined the naming data for a subset of the pilot cohort $(n=10)$ that did not differ from the fMRI cohort on accuracy by the eighth exposure of semantic train- 
ing $(p>.20)$. The naming data from this subgroup exactly replicated the pattern observed for the entire pilot cohort: Orthog raphically trained items were named most slowly $(M=655 \mathrm{msec})$, and nearly equivalent naming times were observed for the phonologically and semantically trained items ( $M=644$ and $645 \mathrm{msec}$, respectively). Moreover, the numerical size of the orthographic disadvantage for this subgroup was identical to that of the entire pilot sample (11 msec in both cases). In light of this finding, we feel confident that the same pattern of transfer effects would have been obtained in the fMRI cohort.

6 . Each subject's accuracy during semantic training (for Exposures $1-8$ ) was fit to a growth function representing a monotonic increase to an asymptote $\left[\mathrm{d}=\mathrm{asy} /(1+\text { rate } / t \text { intercept })^{0.5}\right.$; Ratcliff, 1978], using sums of squares estimates. This yielded a growth function that incorporated rate of learning and ultimate accuracy for each subject, from which we extracted predicted accuracy at the end of the semantic training (the eighth exposure). This measure of predicted accuracy at the end of training was used in the brain-behavior correlation.

(Manuscript received September 8, 2003; revision accepted for publication March 4, 2004.) 